\title{
Austin, Hart y Shapiro Tres variaciones alrededor del derecho como una entidad fundada en una práctica social
}

\author{
Carlos Bernal Pulido* \\ (Traducción del inglés por María José Viana)
}

\begin{abstract}
Resumen: La ontología social es una rama de la filosofía analítica que estudia la naturaleza de las entidades que pertenecen a la realidad social. Desde el punto de vista de la ontología social, este artículo examina tres interpretaciones positivistas de la tesis según la cual el derecho es una entidad fundada en una práctica social. Estas tres interpretaciones se encuentran en las teorías del derecho de Austin, Hart y Shapiro. Esta tarea cumple dos propósitos. Por una parte, destaca nuevos aspectos de las teorías de Austin y de Hart, al precisar hasta qué punto tienen éxito en explicar nuestra intuición de que el derecho es una práctica que construimos y mantenemos todos juntos, mediante nuestro actuar colectivo. Por otra parte, analiza algunos de los elementos fundamentales de la teoría de Shapiro, que entiende al derecho como un plan. Estos elementos permiten comprender el derecho como una entidad ontológica social. Algunos de estos elementos han sido soslayados por los críticos del libro de Shapiro: Legality.
\end{abstract}

Palabras clave: derecho, práctica social, grupos.

Abstract: Social ontology within analytical philosophy studies the
nature of entities, which belong to the social reality. From social
ontology's perspective, this article analyzes three interpretations of
the positivistic thesis according to which the law is an entity grounded
on a social practice. The three interpretations are available in Austin,
Hart and Shapiro's theories of law. The paper has two aims. First,

* Macquarie Law School (Sídney, Australia). 
highlights some new aspects of Austin and Hart's theories based on the idea that the law is a kind of joint action. Second, it analyzes some fundamental elements in Shapiro's thesis concerning the law as a plan. These elements allows understanding the law as a social entity, and some of them has been overlooked by Shapiro's proposal.

Key words: law, social practice, groups.

\section{La ontología social y la naturaleza del derecho}

El derecho nos circunda. Vivimos envueltos en un sinnúmero de actividades jurídicas: vendemos y compramos objetos materiales e inmateriales, conducimos, nos casamos, contratamos empleados, alquilamos casas, pagamos impuestos, obedecemos órdenes y prohibiciones establecidas por el derecho, y ejercemos competencias jurídicas. Estas actividades son reales. Sin embargo, su existencia suscita interrogantes. No podemos explicarlas de la misma forma en que explicamos la realidad de las cosas de la naturaleza (como los árboles o los tigres), es decir, en los términos de las ciencias naturales.

Una intuición plausible es que la existencia de las actividades jurídicas depende de la capacidad que los seres humanos tenemos de actuar de forma colectiva, es decir, como miembros de grupos o sujetos plurales. Esta actividad puede denominarse socialidad ${ }^{1}$. El ejercicio de esta capacidad nos permite crear una parte especial de la realidad, que puede denominarse realidad social. Por medio de nuestro actuar colectivo, en grupos, somos capaces de crear hechos sociales - como el hecho de que existe un país llamado Colombia o que Barack Obama es el actual presidente de los Estados Unidos-e instituciones - como los Estados, los clubes sociales y las Iglesias-. Los hechos sociales y

1 Sobre el concepto de socialidad, cf. Gilbert, M., Living Together. Rationality, Sociality, and Obligation. Lanham, Rowman and Littlefield, 1996, págs. 6 y 263 y ss.; Gilbert, M., Sociality and Responsibility: New Essays in Plural Subject Theory, Lanham, Md., Rowman \& Littlefield Publishers, 2000, pág. 1 y ss., y Toumela, R., The Philosophy of Sociality. The Shared Point of View, Oxford, Oxford UP, 2007, págs. 11 y 66. 
Austin, Hart y Shapiro.Tres variaciones alrededor del derecho ...

las instituciones pertenecen a la realidad social. Esta es una parte de la realidad que existe junto a la realidad natural o física.

Las entidades que conforman la realidad social son "objetivas" desde el punto de vista epistemológico, pero "subjetivas" desde la perspectiva ontológica. En cuanto a la forma en que podemos conocerlas, no son menos objetivas que los objetos naturales o físicos. Sin embargo, su existencia depende de la subjetividad de la mente humana y, en particular, de ciertas actitudes subjetivas de los agentes que participan en las prácticas en que ellas se basan ${ }^{2}$. Por ejemplo, podemos conocer el hecho de que Barack Obama es el actual presidente de los Estados Unidos de una forma tan objetiva como conocemos el hecho de que existe un árbol en el jardín de mi casa. Sin embargo, la existencia de este hecho social depende de las actitudes subjetivas de un particular conjunto de individuos participantes en la práctica política y jurídica que reconoce a Obama como el presidente, y que atribuye a las reglas de la Constitución de los Estados Unidos de América el estatus de enunciados con capacidad para determinar quién es el presidente de dicho país.

La ontología social es una rama de la filosofía analítica que estudia la naturaleza de las entidades que pertenecen a la realidad social. Las contribuciones de Michael Bratman, Margaret Gilbert, Seumas Miller, John Searle, y Raimo Tuomela ${ }^{3}$, durante los años ochenta y noventa,

2 Searle, J. R., Making the Social World. The Structure of Human Civilization. Oxford-New York, Oxford University Press, 2010.

3 Cf. sobre todo: Bratman, M., "Shared Cooperative Activity", The Philosophical Review, 101, 2, 1992b; Bratman, M., Faces of Intention, Cambridge, Cambridge UP, 1999; Gilbert, M., "Walking Together: A Paradigmatic Social Phenomenon", Midwest Studies in Philosophy, 15, 1, 1990; Gilbert, M., On Social Facts, Princeton, Princeton University Press, 1989; Gilbert, M., "Social Rules: Some Problem's for Hart's Account and a New Appraisal", Law and Philosophy, 18, 1999; y más recientemente: Gilbert, M., Sociality and Responsibility: New Essays in Plural Subject Theory, op. cit.; y Gilbert, M., "Acting Together", en Meggle, G. (ed.), Social Facts and Collective Intentionality, Frankfurt a. M., Hänsel-Hohenhausen, 2002; Miller, S., "Joint Action", Philosophical Papers, 21, 3, 1992; Miller, S., "Intentions, Ends and Joint Action", Philosophical Papers, 24, 1, 1995; y más 
establecieron los principios fundamentales de la ontología social. Progresivamente, desde ese entonces, se ha incrementado el número de filósofos y científicos sociales que discuten y aplican estos principios $^{4}$, como parte de la estructura ontológica de una gran variedad de entidades: desde la comunicación, la tecnología, las artes, el lenguaje, las emociones y la violencia, hasta los valores, los conceptos de ciudadanía, los derechos humanos, el gobierno, la legislación, las empresas y otros tipos de entidades políticas y jurídicas.

Con la intuición en mente de que el derecho pertenece a la realidad social y que la realidad del derecho depende de nuestra socialidad, algunos teóricos del derecho también han aprovechado los trabajos filosóficos de fundamentación de la sociología ontológica y han explicado algunos aspectos relacionados con la naturaleza del derecho. Una postura común a estos teóricos del derecho es que el derecho, entendido como un conjunto de normas válidas, está basado en una práctica social. Haré referencia a esta postura como la tesis de la práctica social. Tres propuestas recientes de la tesis de la práctica

recientemente: Miller, S., Social Action: A Teleological Account. Cambridge, Cambridge UP, 2001; Searle, J. R., "Collective Intentions and Actions", en Cohen, P., Morgan, J., y Pollack, M. (ed.), Intentions in Communication, Cambridge, MIT Press, 1990; Searle, J. R. The Construction of Social Reality, New York, Free Press, 1995; y más recientemente: Searle, J. R., "Social Ontology. Some Basic Principles", Anthropological Theory, 6, 1, 2006; y Searle, J. R., Making the Social World. The Structure of Human Civilization, op. cit.; Toumela, R. y Miller, K., "We-Intentions", Philosophical Studies, 53, 1988; Toumela, R., "Actions by Collectives", Philosophical Perspectives, 3, 1989; y más recientemente: Toumela, R., The Philosophy of Social Practices: A Collective Acceptance View, Cambridge, Cambridge UP, 2002; Toumela, R., "We-Intentions Revisited", Philosophical Studies, 125, 2005; y Toumela, R., The Philosophy of Sociality. The Shared Point of View, op. cit.

${ }^{4}$ Cf., por ejemplo, Tsohatzidis, S. L., "Introduction", en Tsohatzidis, S. L. (ed.), Intentional Acts and Institutional Facts. Essays on John Searle's Social Ontology, Dordrecht, Springer, 2007; y Ludwig, K., "Foundations of Social Reality in Collective Intentional Behavior", en Tsohatzidis, S. (ed.), Intentional Acts and Institutional Facts. Essays on John Searle's Social Ontology, Dordrecht, Springer, 2007, pág. 49 y ss. 
Austin, Hart y Shapiro.Tres variaciones alrededor del derecho ...

social han sido expuestas por Christopher Kutz en Complicity ${ }^{5}$, por Rodrigo Sánchez Brigido en Groups, Rules and Legal Practice ${ }^{6}$, y, la más sofisticada, por Scott Shapiro en Legality ${ }^{7}$. Sin embargo, algunas de las intuiciones básicas de estas propuestas no son del todo novedosas. Muchas de ellas pueden ya hallarse en la idea del hábito de obediencia de Austin, y en la concepción de Hart según la cual, primero, la aceptación de las reglas implica la existencia de una práctica social ${ }^{8}$, y, segundo, los sistemas jurídicos están basados en la práctica colectiva de los funcionarios públicos —en especial, de los jueces- mediante la cual aceptan una regla de reconocimiento que establece el principal criterio de validez jurídica9 .

Dentro de este contexto, este escrito pretende emplear el marco teórico de la ontología social con el fin de ofrecer una explicación de las tres interpretaciones positivistas mencionadas que son las más emblemáticas de la tesis de la práctica social, a saber, las interpretaciones que se encuentran en las teorías de Austin, Hart y Shapiro. Este análisis perseguirá dos fines. Por una parte, ilustrará ciertos aspectos de las teorías de Austin y Hart, hasta ahora soslayados por sus analistas y críticos, al preguntarse hasta qué punto estas teorías consiguen explicar la intuición según la cual el derecho es una entidad perteneciente a la ontología social, o en palabras más simples, hasta qué punto la naturaleza del derecho puede entenderse como la de un objeto que construimos todos juntos, mediante nuestro actuar colectivo. Por otra parte, este análisis escudriñará algunos elementos básicos de la teoría del derecho como un plan, expuesta por Shapiro, que permiten entender el derecho como una entidad perteneciente a la ontología social. La mayoría de los analistas de Legality han pasado

${ }^{5}$ Kutz, C., Complicity: Ethics and Law for a Collective Age, Cambridge, Cambridge UP, 2000.

6 Sánchez Brigido, R. E., Groups, Rules and Legal Practice, Dordrecht, London, Springer, 2010.

7 Shapiro, S., Legality, Cambridge, Harvard University Press, 2011.

8 Hart, H. L. A., The Concept of Law, Oxford, Clarendon Press, 1994 [1961], pág. 46.

9 Hart, H. L. A. op. cit., pág. 116. 
por alto estos elementos ${ }^{10}$ y se han centrado en la valoración de la teoría del derecho como un plan desde la perspectiva del debate entre el positivismo jurídico y el derecho natural, y en las discusiones sobre la pregunta de si la coerción debe incluirse en las explicaciones de la naturaleza del derecho.

Antes de emprender este análisis, es necesario aclarar el concepto de práctica social. El concepto de práctica social puede ser, y de hecho ha sido, interpretado de diversas formas. Para los propósitos de este escrito, usaré una concepción de práctica social muy amplia e inclusiva de acuerdo con la cual una práctica social es un conjunto de acciones intencionales colectivas recurrentes ${ }^{11}$. Existen también múltiples puntos de vista acerca del concepto de acción intencional colectiva $^{12}$. Sin embargo, existen, por lo menos, dos condiciones necesarias, que son comunes a las dos posturas más emblemáticas de las acciones intencionales colectivas ${ }^{13}$.

1. La primera es que la acción debe llevarse a cabo por múltiples agentes individuales que actúen conjuntamente como un grupo. Una acción colectiva no es ni una acción de un agente colectivo que la

${ }^{10}$ Cf. Schauer, F., "The Best Laid Plans", The Yale Law Journal, 120, 2010; Tamanaha, B. Z., What is "General" Jurisprudence? A Critique of Universalistic Claims by Philosophical Concepts of Law, manuscrito sin publicar, 2011. Agradezco a Brian Tamanaha por permitirme leer y citar su paper previamente a su publicación; Celano, B., "What can Plans do for Legal Theory?", en Canale, D. y Tuzet, G. (eds.), The Planning Theory of Law, London, Springer, 2013; Murphy, M., "Book Review: Legality", Law and Philosophy, 30, 3, 2011; Waldron, J., "Planning for Legality", Michigan Law Review, 109, 2011; Edmundson, W. A., "Shmegality: A Review of Scott J. Shapiro, Legality", Jurisprudence, 2, 1, 2011.

11 Para una concepción amplia similar, cf:: Toumela, R., The Philosophy of Social Practices: A Collective Acceptance View, op. cit., pág. 3.

12 Para un resumen y una evaluación de estas posturas, $c f:$ Ludwig, K., Understanding Collective Action. From Individual to Institutional Agency, manuscrito sin publicar, 2011, pág. 210 y ss.

13 Sobre estos elementos y su relevancia para el propósito de explicar la naturaleza del derecho, $c f:$ Sánchez Brigido, R., "Collective Intentional Activities and the Law", Oxford Journal of Legal Studies, 29, 2, 2009, págs. 305-306. 
Austin, Hart y Shapiro.Tres variaciones alrededor del derecho ...

lleva a cabo por su cuenta y con sus propias intenciones, ni una mera adición de acciones paralelas y desvinculadas provenientes de diversos agentes individuales.

2. Los agentes individuales que actúan conjuntamente deben actuar de acuerdo con, y en razón de, ciertas intenciones comunes [el vocablo que se usa en la literatura en inglés es "we-intentions"] apropiadas. Las intenciones comunes son intenciones con un contenido especial. Su contenido implica que el grupo debe llevar a cabo la acción relevante mediante las acciones individuales apropiadas de sus miembros ${ }^{14}$.

Adicionalmente, por lo general, para llevar a cabo la acción grupal, los agentes individuales que actúan conjuntamente deben tener cierto conocimiento común acerca de la acción y de las intenciones comunes de sus miembros.

La tesis de la práctica social, entendida con la ayuda de esta concepción amplia de la práctica social, sostiene que el derecho se basa en un conjunto recurrente de acciones intencionales colectivas llevadas a cabo de forma mancomunada por un cierto grupo de agentes individuales apropiados, que actúan como un todo, de acuerdo con, y en razón de, algunas intenciones comunes apropiadas, y que comparten un conocimiento común necesario acerca de la acción y de las intenciones comunes de sus miembros para llevar a cabo tal acción como un grupo. Las teorías del derecho que avalan, explícita o implícitamente, la tesis de la práctica social pretenden explicar varias cosas: ¿qué tipo de agentes participan en ella? ¿Cuál es el contenido de sus intenciones comunes? ¿Cómo surge la normatividad del derecho dentro de este marco institucional? ¿Cómo es posible distinguir la práctica jurídica de otro tipo de prácticas sociales y actividades colectivas intencionales? El propósito específico de este escrito es comprender qué tipo de respuestas ofrecen a estas preguntas las teorías de Austin, Hart y Shapiro, en cuanto a la explicación del derecho como algo que construimos todos, en conjunto.

14 Ludwig, K., Understanding Collective Action. From Individual to Institutional Agency, op. cit., pág. 168. 


\section{Austin y el Derecho como un hábito de obediencia al soberano}

En su libro: The Province of Jurisprudence Determined, John Austin lleva a cabo una explicación de la naturaleza del derecho que podría interpretarse como una versión de la tesis de la práctica social. Los elementos principales de esta explicación son cuatro:

1. Todas las leyes son mandatos ${ }^{15}$.

2. Un mandato es la expresión de un deseo, de que alguien haga o se abstenga de hacer algún acto. Dicho deseo encuentra respaldo en la existencia de la amenaza de que una sanción (un mal) le será "impuesto" al destinatario en caso de que no obedezca el deseo ${ }^{16}$.

3. Todo derecho positivo es establecido por una persona soberana o por un conjunto de personas soberanas ${ }^{17}$.

4. Una persona o conjunto de personas es soberana si se cumplen tres condiciones. Primera, que la persona o el conjunto de personas sea un superior común determinado para todo el colectivo social. Segundo, que exista un hábito general de obediencia a esa persona o a este conjunto de personas, es decir, que el colectivo social tenga el hábito de obedecerle o de someterse a ella o a ellas. Y, tercero, que la persona o conjunto de personas que es superior no tenga el hábito de obedecer a otro determinado superior.

Es posible demostrar que la teoría del mandato de Austin es una versión de la tesis de la práctica social si se reconstruyen estos elementos, desde el último hasta el primero, usando la perspectiva del concepto de práctica social. Esta tarea puede cumplirse en dos pasos. El primer paso consiste en analizar el hábito de obediencia como una actividad o como un conjunto de acciones recurrentes. De esta manera, decir que el colectivo social debe tener el hábito de

15 Austin, J., The Province of Jurisprudence Determined, Cambridge, Cambridge UP, 1995, pág. 21.

${ }^{16}$ Austin, J., op. cit., pág. 21.

${ }^{17}$ Austin, J., op. cit., pág. 165. 
Austin, Hart y Shapiro.Tres variaciones alrededor del derecho ...

obedecer al soberano es lo mismo que decir que es necesario que el colectivo obedezca recurrentemente al soberano. Esto significa que el colectivo debe llevar a cabo recurrentemente las acciones o abstenerse de ejecutar las acciones establecidas por los mandatos del soberano, y cuya ejecución está respaldada por la amenaza de sanciones. Correlativamente, el soberano no debe obedecer a nadie más, sino que debe ejecutar recurrentemente la acción de emitir mandatos, es decir, expresar deseos dirigidos a los ciudadanos, de acuerdo con los cuales ellos deben hacer u omitir ciertas acciones, so pena de que una sanción les sea impuesta en caso de incumplimiento.

El segundo paso consiste en la comprensión del hábito general de obediencia como una actividad intencional colectiva desarrollada por el soberano que emite los mandatos y por el colectivo social que los obedece. Los tres elementos del concepto de actividad intencional colectiva se encuentran claramente dentro del hábito general de obediencia. Primero, esta es una actividad ejecutada por múltiples individuos. Dado que el hábito de obediencia debe ser general, este tipo de acción recurrente no puede ser llevada a cabo solo por parte de un individuo. Esta es una actividad que debe ejecutarse necesariamente por varios individuos que actúan de consuno, y que conforman la "generalidad" o "la mayoría" de los miembros de la sociedad ${ }^{18}$. Segundo, estas acciones recurrentes no son llevadas a cabo por "la mayoría de la sociedad", entendida como un tipo de superagente, sino por medio de acciones específicas de individuos independientes que pertenecen a dicha mayoría, y que actúan de consuno como un grupo o como un grupo de grupos. Y tercero, ellos llevan a cabo las acciones intencionalmente mediante el cumplimiento de las exigencias expresadas en los mandatos del soberano, motivados por la amenaza de las sanciones. Como Davidson explica ${ }^{19}$, las intenciones se basan en deseos y creencias. En el presente caso, los agentes que obedecen

${ }^{18}$ Austin, J., op. cit., pág. 169.

${ }^{19}$ De acuerdo con Davidson, la realización de una acción comienza con algún tipo de (pro-)actitud motivacional (un deseo) dirigido al devenir del estado de cosas que las acciones llevan consigo, y con la creencia de que este estado de cosas tendrá lugar efectivamente como resultado de la acción. 
al soberano tienen el deseo de ejecutar las acciones que este exige. De la misma forma tienen las creencias apropiadas acerca de cuál es la manera correcta de obedecer al soberano. Dicho deseo y estas creencias conducen a la formación de intenciones que desencadenan en los agentes ciertos movimientos corporales específicos que, a su vez, resultan en la ejecución de lo mandado.

Desde este punto de vista, la teoría de Austin tiene el mérito de haber avanzado en el conocimiento sobre la naturaleza del derecho mediante el señalamiento de que una propiedad esencial del derecho se funda en la existencia de acciones intencionales recurrentes de una pluralidad de sujetos.

Sin embargo, la teoría del derecho de Austin enfrenta, al menos, dos dificultades si quiere proponerse como una explicación plausible del derecho como una práctica social: el problema de la colectividad y el problema de la normatividad. Primero, el hábito de la obediencia no es necesariamente una acción colectiva en el sentido socio-ontológico de la expresión. En otras palabras, que exista un hábito de obediencia al soberano en una población no es suficiente para que los miembros del colectivo social actúen en conjunto intencionalmente en un sentido relevante. El concepto de hábito general de obediencia es ambiguo. Existen, por lo menos, dos lecturas de este concepto: una distributiva y otra colectiva ${ }^{20}$. De acuerdo con la lectura distributiva, el hábito general de obediencia implica que la mayoría de los individuos de la comunidad tiene un hábito de obediencia personal e independiente hacia los mandatos emitidos por el soberano. El interés personal o el miedo a las sanciones pueden motivar a los destinatarios de los mandatos a obedecer recurrentemente al soberano de manera individual. Desde la perspectiva de esta interpretación, el hábito general de obediencia es una mera suma de acciones personales recurrentes de obediencia por parte de los miembros individuales del colectivo

Davidson, D., Essays on Actions and Events, Oxford, Oxford UP, 2001, pág. 83 y ss.

20 Para una comprensión relacionada pero no idéntica de estas lecturas, $c f$. Ludwig, K., Understanding Collective Action. From Individual to Institutional $30 \quad$ Agency, op. cit. 
Austin, Hart y Shapiro.Tres variaciones alrededor del derecho ...

social. Esto difiere de la lectura colectiva. En la lectura colectiva, el hábito general de obediencia es una acción intencional colectiva. Esto implica que los individuos que conforman el colectivo social actúan conjuntamente de acuerdo con, y en razón de, algunas intenciones comunes, cuyo contenido es que, como grupo, el colectivo social ejecuta la actividad de obedecer los mandatos emitidos por el soberano mediante las acciones individuales apropiadas de sus miembros.

A estas alturas surge un problema de interpretación, a saber, si la mejor lectura del hábito de obediencia de Austin es la lectura distributiva o la colectiva. Austin no hace expresa mención a este aspecto. El hecho de que el soberano deba ser un superior "común" puede ser un indicio de que Austin tenía en mente la lectura colectiva. No obstante, esta conclusión no deriva de tal presupuesto. Es posible que haya un solo superior que amenace a la población con sanciones y que cada miembro del colectivo social le obedezca independientemente, de manera individual ${ }^{21}$. La existencia de un superior común no presupone necesariamente coordinación e interconexión de acciones e intenciones comunes por parte de los diversos agentes que conforman el colectivo social.

Además del problema de la colectividad, un segundo problema del hábito general de obediencia de Austin es su incapacidad para explicar la normatividad del derecho. H. L. A. Hart llamó la atención sobre este problema al señalar que el hábito general de obediencia no puede captar algunas verdades aceptadas sobre la dimensión normativa del derecho, tales como el hecho de que la desviación del comportamiento

${ }^{21}$ H. L. A. Hart, sin disponer del marco teórico de las teorías de la ontología social, tiene también esta intuición en mente cuando defiende que el hábito general de obediencia es demasiado simple para ser un concepto apropiado para explicar la naturaleza del derecho porque: "En aras de que exista un hábito semejante no es necesario que los miembros del grupo actúen porque exista un tipo general de comportamiento. Ni siquiera es necesario que ellos piensen que el comportamiento que se exige es general. Mucho menos, es necesario que los miembros del grupo intenten animar a otros a que persigan dicho comportamiento ni mantenerlo. Es suficiente con que cada individuo, por su parte, se comporte de la manera en que otros de hecho lo hacen". Cf. Hart, H. L. A., op. cit., pág. 56. 
establecido en las normas produce una reacción crítica y que la gente piensa que dicha reacción crítica está justificada o, en otras palabras, que hay buenas razones para criticar las mencionadas desviaciones ${ }^{22}$. Asimismo, el hábito general de obediencia no puede explicar la verdad aceptada de que la autoridad jurídica no es solo aquella que tiene la competencia para ejercer la coerción y obligar la sujeción a las normas, sino también "el derecho jurídico para hacerlo"23; y que este derecho, o, para ser más precisos, la competencia jurídica para imponer sanciones y la competencia jurídica general para emitir reglas a la población, genera no solo un hábito, sino también una sujeción (en términos de Hohfled) a obedecer a la autoridad jurídica, y la obligación de seguir las reglas jurídicas emitidas por ella.

Estas consideraciones conducen a la conclusión de que la teoría del derecho de Austin no puede explicar el derecho como una práctica social en el sentido de una práctica colectiva ni en el de una práctica normativa.

\section{Hart y la aceptación de reglas}

La crítica de Hart a la teoría del derecho de Austin lo lleva a sostener que el derecho está fundado en una "práctica más compleja", a saber, una práctica social normativa consistente en la aceptación de reglas sociales.

Hart sostiene que la aceptación de una regla social implica los elementos que también la existencia de un hábito presupone, es decir, que una pluralidad de individuos lleve a cabo, de forma recurrente, un conjunto de acciones. En este sentido, la aceptación de una regla social implica la existencia de regularidades en el comportamiento social. Sin embargo, dicha aceptación exige la presencia de otros tres elementos: (1) que la desviación de la regla dé lugar a la crítica y la imposición de sanciones, $\mathrm{y}$, como consecuencia, una presión hacia la conformidad con la regla; (2) que la crítica a la desviación 
Austin, Hart y Shapiro.Tres variaciones alrededor del derecho ...

y la imposición de sanciones sea considerada legítima, justificada o fundada en buenas razones; y (3) el denominado aspecto "interno" de las reglas, que consiste en que los agentes "consideren al comportamiento establecido por la regla como un estándar general que debe ser obedecido por el grupo social, entendido como un todo" 24 . El aspecto interno de las reglas cambia la perspectiva desde la cual los miembros de la sociedad observan las regularidades relativas a un comportamiento social. Ellos llevan a cabo ciertas acciones intencionales recurrentes asociadas con la obediencia de las reglas porque reconocen a tales reglas como estándares generales que deben ser seguidos por la sociedad, entendida como un todo.

Si se analiza estos tres nuevos elementos introducidos por Hart, se notará con claridad que los dos primeros también implican llevar a cabo un conjunto de acciones colectivas recurrentes, o, en otras palabras, una actividad llevada a cabo por diversos individuos. De esta manera, el concepto de Hart de aceptación de reglas implica tres tipos de actividades sociales o regularidades en el comportamiento social: el hábito de obediencia, el hábito de criticar las desviaciones y el hábito de considerar legítima dicha crítica.

No obstante, el tercer elemento tiene una naturaleza diferente. Se refiere a la actitud que los miembros de la sociedad tienen frente al derecho. Hart denomina esta actitud: el punto de vista interno ${ }^{25}$. Como Shapiro ha aclarado, el punto de vista interno no se refiere simplemente al punto de vista de los miembros de la sociedad o de los participantes en la práctica jurídica social. El referente de este punto de vista es, más bien, un tipo especial de actitud que estos participantes pueden tener: la actitud de aceptación de las reglas ${ }^{26}$. La actitud de aceptación de reglas es una disposición, en sentido filosófico, a lo que el aspecto interno de las reglas describe, a saber, al establecimiento de un patrón de comportamiento para que sirva como estándar de conducta, es decir, como una guía de conducta dirigida a todos los miembros de

${ }^{24}$ Hart, H. L. A., op. cit., pág. 55-66.

${ }^{25}$ Hart, H. L. A., op. cit., pág. 89.

${ }^{26}$ Shapiro, S., "What is the Internal Point of View?", Fordham Law Review, 75, 2006, pág. 1159. 
la sociedad, y al establecimiento de una razón legítima para ajustarse al patrón de comportamiento y para criticar su desviación. Hart lo define de la siguiente manera en el epílogo al Concepto del Derecho:

[La aceptación] consiste en la disposición de los individuos a considerar tales patrones de conducta tanto como guías para su conducta futura como también a manera de estándares para la crítica... ${ }^{27}$

Hasta este punto, surgen diversas preguntas. ¿Cómo debe entenderse el concepto de aceptación de reglas? ¿Puede entenderse el concepto de aceptación de reglas como una acción intencional colectiva o como un compromiso con alguna forma de acción intencional colectiva? Por último, ¿resuelve la aceptación de reglas el problema que la teoría del derecho de Austin tiene para explicar la normatividad del derecho?; y, en este sentido, ¿es un desarrollo de la teoría del derecho y un avance en comparación con la teoría del derecho como un conjunto de mandatos, tal como la entiende Austin?

En el epílogo a El Concepto de Derecho, Hart sugiere que la aceptación de reglas es una disposición. Por una parte, esto puede entenderse como la actitud de la mayoría de los miembros de la sociedad de estar dispuestos $\mathrm{a}-\mathrm{O}$ en tener la propensión de- asumir ciertos patrones de comportamiento consistentes en adoptar las normas jurídicas como guías de conducta futura, en la tendencia a actuar de acuerdo con dichas normas y a criticar toda desviación de ellas. De esta manera, estos patrones de comportamiento pueden servir como una razón para la acción conforme a las normas jurídicas y como una crítica para el comportamiento que de ellas se desvía. Sin embargo, esta versión del concepto de regla de aceptación parece muy débil, ya que admite una interpretación muy problemática de acuerdo con la cual lo único necesario es la actitud de los miembros de la sociedad en el sentido de que es posible que ellos asuman los patrones de comportamiento de derecho como guías de conducta, y no ya la actitud consistente en que ellos de hecho asumen dichos patrones como guías para su conducta 
Austin, Hart y Shapiro.Tres variaciones alrededor del derecho ...

futura $^{28}$. Esto no parece ser consistente con el análisis de Hart acerca del aspecto interno de las reglas, en el cual, es evidente que lo que se exige es que los miembros de la sociedad de hecho consideren los patrones de comportamiento establecidos por el derecho como estándares generales para ser seguidos por el pleno de la sociedad.

Por otra parte, Shapiro ha sugerido que en la teoría de Hart la aceptación de una regla debe interpretarse en el sentido de que implica el compromiso de actuar conforme a la regla. Shapiro considera que este compromiso es equivalente a tener la intención de ajustarse a la regla. En palabras de Shapiro:

Alguien tiene el punto de vista interno hacia una regla cuando tiene la intención de ajustarse a la regla, de criticar a otros por no ajustar su comportamiento a ella... ${ }^{29}$

La sugerencia de Shapiro ciertamente es capaz de dar cuenta de los patrones de comportamiento que nosotros esperamos al aceptar el concepto de regla propuesto por Hart. De hecho, el compromiso de que habla Shapiro es una forma de aceptación de una regla. Sin embargo, esta asunción parece intelectualizar demasiado lo que Hart tenía en mente. La interpretación de Shapiro atribuye a los agentes una consciencia interna con relación a las reglas que va más allá de la que en realidad puede existir. Contrario a lo que Shapiro parece sugerir, es posible pensar en que los destinatarios del derecho aceptan las reglas sin siquiera pensar en que en ellos se ha formado la intención de obedecerlas. Hay muchas reglas que regulan la vida social, conforme a las cuales actuamos, y que son el resultado de diversos tipos de presión social. Esta presión social se considera como una forma de entrenamiento, sobre la que todavía no hemos reflexionado. No nos hemos creado sobre ella ninguna representación en nuestra mente, ni la hemos articulado explícitamente. Antes bien, lo que

28 Sobre el hecho de que las disposiciones implican la posibilidad de una propiedad y no ya, de hecho, una propiedad: Fara, M., "Dispositions", Stanford Encyclopedia of Philosophy, 2006, http://plato.stanford.edu/entries/dispositions/, 08/08/2011.

29 Shapiro, S., "What is the Internal Point of View?", op. cit., pág. 1163. 
acontece es que, en diversas circunstancias, hemos formado hábitos de comportamiento que crean la disposición de asumir dichos comportamientos como patrones que regulan conductas futuras - como si tuviéramos en realidad un compromiso intencional condicional a seguir las reglas siempre que surjan circunstancias relevantes- - Sin embargo, en realidad no hemos formado en nuestra mente una representación de dichas reglas ni la intención de obedecerlas. Estas reglas forman parte de lo que John Searle ha denominado el trasfondo de la intencionalidad ${ }^{30}$. Dentro de este contexto, este trasfondo expresa la idea de que existe un elemento intencional de aceptación de reglas, a saber, el punto de vista interno, que se expresa en una disposición pero que no involucra un compromiso explícito de adecuar la conducta futura al contenido de la regla ${ }^{31}$.

Con relación a la segunda pregunta, esto es, si la aceptación de reglas implica colectividad, el problema radica en que la aceptación de reglas permite tanto una lectura distributiva como una colectiva. Frente a este respecto, desde el punto de vista del concepto de colectividad, la teoría de Hart es similar a la idea de Austin relativa al hábito general de obediencia. Es posible que cada uno de los miembros de la sociedad obedezca las reglas, critique su desviación, considere dicha crítica legítima, y tenga una disposición individual a tomar ciertas reglas sociales como patrones de comportamiento para sí y para el resto de la sociedad. Desde el punto de vista de esta interpretación, la aceptación de reglas resultaría de la combinación de dos elementos. El primero es un elemento externo: un conjunto de acciones recurrentes que se suman unas a otras, y que implican la conformidad con ciertas reglas sociales, la crítica de las desviaciones y la consideración de las críticas como legítimas. El segundo es un elemento interno: un conjunto de disposiciones individuales, que se suman unas a otras,

${ }^{30}$ Searle, J. R., Intentionality. An essay in the philosophy of mind, Cambridge, Cambridge University Press, 1983, capítulo 5. El trasfondo de la intencionalidad se entiende como un conjunto de habilidades, capacidades y presuposiciones que hacen posible la representación de ideas en nuestra mente, a pesar de que de ellas no tengamos ninguna representación mental.

31 Agradezco a Kirk Ludwig por sus sugerencias con relación a este punto. 
Austin, Hart y Shapiro.Tres variaciones alrededor del derecho ...

disposiciones a conformarse a las reglas y a criticar su desviación. Desde esta perspectiva, el elemento interno es una actitud individual y no una actitud cooperativa. En la lectura distributiva, la aceptación de una regla implica la formación de una disposición individual a permitir que la regla dirija un comportamiento o, en otras palabras, implica la formación de una intención condicional a actuar de acuerdo con la reglas si se dan las circunstancias para su aplicación. En contraste, desde la perspectiva de la lectura colectiva, la aceptación de una regla implica la formación grupal de intenciones comunes de actuar de acuerdo con las reglas en determinadas circunstancias. Esta lectura, sin embargo, exige entender que las reglas gobiernen un conjunto de acciones colectivas. Esto, a su vez, implica asumir que los miembros de la mayoría de la sociedad consideren la aceptación de las reglas sociales de derecho como una actividad relativa a un grupo, o, en otras palabras, como una acción intencional recurrente que el grupo deba llevar a cabo mediante acciones individuales de sus miembros consistentes en actuar de acuerdo con las reglas, criticar las desviaciones y considerar las críticas como legítimas, y que la disposición de conformarse a dichas reglas y de criticar las desviaciones es una actitud colectiva. Una actitud colectiva implica que cada miembro de la mayoría de la sociedad tiene una actitud individual relacionada con la aceptación de las reglas sociales del derecho, entendida como una actividad relativa al grupo social. En este sentido, tengo una actitud colectiva hacia la aceptación de reglas, si tengo una actitud a favor de que nosotros, como grupo, consideremos las reglas sociales relevantes como guías de nuestra conducta, actuemos conforme a ellas y critiquemos las conductas que se desvían de los patrones de comportamiento establecidos por ellas.

Hart no ofrece mayores aclaraciones sobre este punto, y, al final de cuentas, su teoría no excluye la lectura distributiva. En un sentido similar al de Austin, cuando este trata la idea de que la población debe tener el hábito de obediencia hacia un superior común, Hart se concentra en el problema de la identificación de un conjunto común de reglas sociales como reglas jurídicas. Hart sostiene que el derecho es una combinación de dos tipos de reglas sociales: primarias 
y secundarias. Mientras las reglas primarias exigen que sus destinatarios hagan o se abstengan de llevar a cabo ciertas acciones (crean obligaciones), las reglas secundarias confieren poderes para crear, cambiar y reconocer las reglas primarias ${ }^{32}$. La regla clave para resolver el problema de la identificación de un solo grupo de reglas sociales como reglas jurídicas es la regla segundaria de reconocimiento. La regla de reconocimiento pretende remediar el problema de la incertidumbre acerca de cuáles son las reglas jurídicas; es "una regla para la identificación concluyente de reglas primarias"33. Esta regla tiene que ser aceptada solo por las autoridades oficiales. El resto de los miembros de la sociedad pueden limitarse simplemente a obedecer las reglas primarias que pasen el examen establecido por la regla de reconocimiento. La aceptación de la regla de reconocimiento por las autoridades oficiales es la clave para la identificación del conjunto de reglas que pertenecen al ordenamiento jurídico. En palabras de Hart: "Siempre que se reconozca una regla semejante, tanto los particulares como las autoridades oficiales están provistos de un criterio dotado de autoridad para identificar las reglas primarias de obligación"34. En este sentido, la fundamentación de la práctica social del derecho consiste en la práctica social de aceptación de la regla de reconocimiento por parte de las autoridades oficiales. Sin embargo, incluso la aceptación de la regla de reconocimiento permite las lecturas distributiva y colectiva. Es posible que cada funcionario que es una autoridad oficial acepte individualmente la regla de reconocimiento del sistema jurídico, por ejemplo, la regla de reconocimiento del sistema británico, de acuerdo con la cual lo que la Reina dicte en el Parlamento es derecho. Esta aceptación no es necesariamente colectiva en el sentido socio-ontológico de la expresión.

De la misma manera, Shapiro sostiene que la regla de reconocimiento es social en dos sentidos:

${ }^{32}$ Hart, H. L. A., op. cit., págs. 81 y 94.

33 Hart, H. L. A., op. cit., págs. 95.

${ }^{34}$ Hart, H. L. A., op. cit., págs. 100. 
Austin, Hart y Shapiro.Tres variaciones alrededor del derecho ...

Primero, la regla de reconocimiento existe y tiene contenido en razón de, y solo en razón de, ciertos hechos sociales. En particular [...] el hecho de que los miembros de un grupo dirijan el punto de vista interno hacia cierto comportamiento de carácter regular y lo usen para evaluar la validez de las normas que caen dentro de su ámbito. Segundo, la regla de reconocimiento es social en el sentido de que establece un estándar que debe ser seguido por todo el grupo social ${ }^{35}$.

Ninguna de estos dos sentidos necesariamente implica colectividad. Es posible decir que los miembros de la sociedad, en una interpretación distributiva, dirigen el punto de vista interno hacia cierto comportamiento de carácter regular. Además, el establecer un estándar dirigido a todo el grupo social no depende de actitudes sociales comunes necesariamente relacionadas con la lectura colectiva. El soberano de Austin establece también sus mandatos como estándares dirigidos a todo el grupo social.

Esta concepción de la práctica del derecho como una aceptación de la regla de reconocimiento por parte de las autoridades oficiales crea otro problema que se relaciona con el concepto de colectividad. Dado que solo es necesario que las autoridades oficiales acepten la regla de reconocimiento y no la totalidad de la población, el derecho no puede ser considerado como una práctica social, sino solo como una práctica oficial, es decir, que no es una práctica social de todo el grupo dentro del cual existe el sistema jurídico ${ }^{36}$. El único requisito concerniente a todo el conjunto de la sociedad que Hart establece para la existencia de un sistema jurídico es que exista una obediencia generalizada hacia las reglas primarias. Es bien cierto que Hart sostiene que es frecuente que la regla de reconocimiento sea solo aceptada en general por los ciudadanos (de una manera), mediante su obediencia a las decisiones de las autoridades oficiales. Con todo, en su teoría,

${ }^{35}$ Shapiro, S., Legality, op. cit., pág. 84.

${ }^{36}$ Ver Wilkinson, M. A., "Is Law Morally Risky? Alienation, Acceptance and Hart's Concept of Law", Oxford Journal of Legal Studies, 30, 3, 2010, pág. 447. 
la regla de reconocimiento debe ser aceptada efectiva y activamente como un estándar para el pleno de la sociedad solo por las autoridades oficiales ${ }^{37}$. Como consecuencia, en la teoría de Hart la base de todo el sistema jurídico consiste en la práctica de las autoridades oficiales de llevar a cabo recurrentemente las acciones externas de creación, cambio y aplicación de normas primarias de acuerdo con la regla de reconocimiento, junto a un elemento interno, es decir, tomar como estándar para toda la sociedad la regla de reconocimiento, con la disposición de adecuarse a ella y de criticar toda desviación que se presente con relación a la misma.

Este elemento permite a la teoría de Hart explicar por qué una conducta que es ampliamente practicada en la sociedad puede, al mismo tiempo, ser prohibida por el derecho. Lo que se necesita es que esta conducta esté prohibida mediante una regla proferida por una autoridad, y que la creación de dicha regla ocurra de acuerdo con el criterio establecido por la regla de reconocimiento. Dado que solo es necesario que la regla de reconocimiento sea aceptada por las autoridades oficiales, entonces estas pueden aceptar que una conducta practicada ampliamente en la sociedad sea prohibida. De esta manera, puede haber reglas jurídicas que no sean practicadas o que estén en conflicto con prácticas corrientes.

No obstante, la caracterización del derecho como una práctica oficial y no como una práctica ampliamente aceptada por la sociedad también crea un problema para la teoría de Hart. Primero, no puede explicar por qué la práctica oficial da lugar a reglas que son jurídicamente vinculantes para toda la sociedad. Si solo las autoridades oficiales deben aceptar la regla de reconocimiento y las reglas primarias creadas de acuerdo con ella, entonces únicamente ellas estarían cubiertas por la normatividad del derecho. Existe una asimetría entre los agentes que llevan a cabo la práctica que se encuentra en la fundamentación del sistema jurídico y los agentes que están vinculados por las reglas de este sistema. 
Austin, Hart y Shapiro.Tres variaciones alrededor del derecho ...

Este problema muestra que la teoría de Hart resulta similar a la de Austin en diversos aspectos. De acuerdo con Hart, la diferencia entre su teoría y la teoría del derecho de Austin, desde la perspectiva de los sujetos estriba en que, mientras el destinatario de un mandato austiniano solo se ve obligado, el de una regla hartiana tiene una obligación. Y la diferencia entre verse obligado y tener una obligación consiste precisamente en que, en la segunda situación, el aspecto interno de las reglas está presente en el destinatario. No obstante, si los ciudadanos no aceptan la regla de reconocimiento, sino que solo obedecen las reglas primarias, entonces ellos no tienen en realidad la actitud interna hacia las regla de reconocimiento y, consecuentemente, es difícil ver cómo pueden tenerla hacia las reglas primarias y secundarias expedidas de acuerdo con la regla de reconocimiento. Los ciudadanos solo obedecen estas reglas porque han sido creadas por las autoridades oficiales. Ellos solo tienen el hábito sin que a este vaya aparejada ninguna actitud.

En cuanto a la tercera pregunta, la teoría de Hart de la práctica social no puede explicar la normatividad del derecho. Esta imposibilidad emerge de su concepción de la regla de reconocimiento. Hart caracteriza la regla de reconocimiento con tres propiedades ${ }^{38}$. Primero, es una regla secundaria o una regla acerca de reglas. Esta regla establece el criterio para identificar las reglas primarias del sistema jurídico. Segundo, es una regla suprema. Es el fundamento de la validez de todas las reglas primarias y secundarias del sistema jurídico. Finalmente, la regla de reconocimiento es una regla que impone deberes y cuyos destinatarios son los abogados. Esta regla crea el deber de reconocer y aplicar como reglas jurídicas todas las reglas creadas de acuerdo con el criterio establecido por ella.

Shapiro sostiene que esta construcción de la regla de reconocimiento está llamada a fracasar ${ }^{39}$. De acuerdo con Shapiro, en la teoría de Hart las reglas sociales se reducen a prácticas sociales. Por

${ }^{38}$ Para un análisis de la regla de reconocimiento, ver Shapiro, S. Legality, op. cit., págs. 84-85.

${ }^{39}$ Shapiro, S. Legality, op. cit., pág. 102. 
una parte, esta es una buena estrategia que Hart sigue para crear una justificación para la normatividad del derecho, sin violar el principio de Hume, de acuerdo con el cual, no se puede derivar un "deber ser" de un "ser". Con base en el análisis de la teoría de Hart llevado a cabo por Kevin Toh ${ }^{40}$, Shapiro sostiene que Hart acoge un tipo de expresivismo según el cual el tipo de normatividad que producen las reglas jurídicas es solo jurídico, pero no moral, y lo que quiere decir el concepto de normatividad es que las autoridades oficiales orientan su punto de vista interno hacia las reglas jurídicas. Esto implica que ellos hacen juicios normativos de acuerdo con los cuales adoptan las reglas jurídicas como estándares para guiar y evaluar la conducta. Esto se lleva a cabo mediante juicios normativos sobre la validez jurídica. Hart los denomina enunciados internos. Los enunciados internos son enunciados fácticos, en el sentido de que solo expresan la existencia del compromiso de tomar a las reglas como un estándar para las conductas futuras ${ }^{41}$. De esta manera, la regla de reconocimiento, como una práctica social es un hecho que da lugar a otros hechos, señaladamente, las acciones colectivas intencionales recurrentes, llevadas a cabo por las autoridades oficiales que juzgan los casos sobre la base de las reglas jurídicas, y la aceptación interna de esas reglas como guías para la conducta futura. En consecuencia, en la teoría de Hart un "ser" deriva de un "ser". Esto respeta el principio de Hume y no incurre en una falacia naturalística.

Sin embargo, por otra parte, de acuerdo con Shapiro, reducir la regla de reconocimiento y otras reglas sociales a prácticas sociales es un error de categoría. Shapiro sostiene que esto es así porque "las reglas y las prácticas pertenecen a diferentes categorías metafísicas" 42 . Mientras las reglas son objetos abstractos, objetos del pensamiento y no entidades que existan dentro del espacio y el tiempo, las prácticas son eventos concretos: ellas tienen lugar dentro del mundo natural e interaccionan causalmente con otros eventos físicos.

${ }^{40}$ Toh, K., "Hart's Expressivism and His Benthamite Project", Legal Theory, 11, 2005, págs. 75-123.

${ }^{41}$ Shapiro, S. Legality, op. cit., pág. 100.

${ }^{42}$ Shapiro, S. Legality, op. cit., pág. 103. 
Austin, Hart y Shapiro.Tres variaciones alrededor del derecho ...

Es posible dar la razón a Shapiro en que las reglas y las prácticas pertenecen a diferentes categorías metafísicas y que, mientras las reglas sociales son objetos abstractos, las prácticas sociales son eventos concretos. Las reglas sociales son objetos del pensamiento que pueden usualmente reconstruirse con la forma lógica de los enunciados condicionales: "si se dan las circunstancias $C$, entonces se exige la acción A". Como se estableció en el comienzo de este escrito, las prácticas sociales son conjuntos de acciones colectivas intencionales recurrentes. Pues bien, las acciones son eventos ${ }^{43}$. Por esta razón, las prácticas sociales son conjuntos de eventos, y los eventos son particulares. Un evento es un cambio de estado en un objeto o en una región del espacio que permanece a lo largo del tiempo.

No obstante, resulta pertinente sugerir una interpretación alternativa a la propuesta de Hart, de acuerdo con la cual, en su teoría, las reglas sociales no se reducen a prácticas sociales, sino que se fundan en ellas: lo que Hart realmente sostiene es que una práctica social consistente en la aceptación de una regla de reconocimiento es el fundamento del sistema jurídico, es decir, que la validez de todas las reglas de derecho se fundamenta en la práctica oficial de aceptación de la regla de reconocimiento. Esto significa que Hart no comete ningún error de categoría. Él no sostiene que los objetos abstractos (reglas) se puedan reducir a eventos concretos (prácticas sociales), sino únicamente que tales objetos abstractos son válidos en la medida en que exista una práctica - a saber, un conjunto de acciones intencionales concretas llevadas a cabo por las autoridades oficiales, mediante las cuales se acepta la regla de reconocimiento- y se tomen tales objetos abstractos (reglas jurídicas producidas de acuerdo con la regla de reconocimiento) como un estándar para las conductas futuras de toda la sociedad. De acuerdo con esta interpretación, la regla de reconocimiento y todas las demás reglas del sistema solo se fundamentan en esta práctica desarrollada por las autoridades oficiales.

${ }^{43}$ Sobre la tesis de que las acciones son una subclase de eventos, ver: Davidson, D., op. cit., págs. 118-122; Kim, J., Supervenience and Mind. Selected Philosophical Essays, Cambridge, Cambridge UP, 1993, pág. 49. 
Sin embargo, Shapiro también tendría una objeción en contra de esta interpretación, por cuanto él sostiene, con la ayuda del siguiente ejemplo extraído del béisbol, que "las prácticas sociales no necesariamente generan reglas sociales":

En beisbol, por ejemplo, el jugador que se encuentra en tercera base se dirige hacia la base principal cuando sospecha que ha habido un lanzamiento. Si falla en la aproximación será criticado por no hacerlo; la aproximación, en otras palabras, es una práctica social hartiana. En todo caso, no existe una regla que exija a los jugadores de tercera base aproximarse cuando sospechan que ha habido un lanzamiento. Lo contrario ocurre con los bateadores que se retiran después de tres strikes. Esta última actividad es una regla reconocida y aceptada ${ }^{44}$.

A pesar de ello, quizá Hart no tenga la necesidad de demostrar que las prácticas sociales necesariamente generan reglas sociales, si quiere explicar la normatividad del derecho y la posibilidad de que existan autoridades jurídicas, sobre la base de la práctica social consistente en aceptar la regla de reconocimiento. Para Hart es suficiente demostrar que es conceptualmente posible que las prácticas sociales generen reglas sociales o, en otras palabras, que las prácticas sociales puedan generar reglas sociales.

No obstante, Hart no consigue demostrar esto último. Hart no explica por qué si las autoridades oficiales aceptan la regla de reconocimiento, quedan vinculadas por ella y por todas las demás reglas creadas de acuerdo con la regla de reconocimiento. No explica por qué la aceptación de la regla de reconocimiento atribuye normatividad jurídica a esta regla y, como consecuencia, esta se convierte en una regla que impone deberes a las autoridades oficiales. Ciertamente, desde el punto de vista de Hart, la aceptación de la regla de reconocimiento implica que las autoridades oficiales están dispuestas a tomarla como una premisa de razonamiento práctico. Sin embargo, esto no implica que ellas deban adoptarla como una premisa del razonamiento 
Austin, Hart y Shapiro.Tres variaciones alrededor del derecho ...

práctico ni que ellos deban estar dispuestos a obedecerla. La disposición que las autoridades del Estado tengan para adoptar la regla de reconocimiento como una premisa del razonamiento práctico no las obliga a obedecerla ni a seguir estando en disposición de aplicarla.

Aún peor (aquí la asimetría entre la práctica de las autoridades oficiales y la práctica de los ciudadanos se vuelve relevante), Hart no puede explicar el hecho de que de la aceptación de la regla de reconocimiento por parte de las autoridades oficiales se siga que los ciudadanos también están vinculados por la regla de reconocimiento y todas las demás reglas generadas dentro del sistema jurídico, cuya fundamentación estribe en la regla de reconocimiento. Incluso si, por razón del argumento, se admitiera que la aceptación de la regla de reconocimiento la hace vinculante para las autoridades oficiales, de ello no puede derivarse que dicha regla sea también vinculante para los ciudadanos que no la han aceptado.

Finalmente, la teoría de Hart no es capaz de explicar la naturaleza de la autoridad jurídica o, en pocas palabras: por qué las autoridades oficiales son autoridades oficiales. Su punto de partida es que la fundamentación del sistema jurídico es la práctica de las autoridades estatales consistente en aceptar la regla de reconocimiento. Sin embargo, ¿de qué manera las autoridades oficiales devienen en lo que son? ¿De dónde emana su autoridad? La fuente de esta autoridad no puede ser la regla de reconocimiento por dos razones: primero, porque las autoridades oficiales existían antes de que la regla de reconocimiento existiera. Precisamente, una práctica llevada a cabo por las autoridades oficiales es la que da lugar a la regla de reconocimiento. Y, segundo, la fuente no puede ser la regla de reconocimiento porque, en la teoría de Hart, la regla de reconocimiento no es una regla que confiere poderes, sino una regla que impone deberes. Por ello, esta no puede ser, lógicamente, la fuente del poder conferido a las autoridades oficiales. Como consecuencia, no es claro por qué la regla de reconocimiento, y todas las demás reglas del sistema jurídico, deben ser obedecidas, ni por qué tienen fuerza vinculante. 


\section{La teoría del derecho como un plan}

En su libro Legality, Scott Shapiro ofrece una teoría del derecho como una entidad basada en una práctica social normativa. Su explicación del derecho pretende resolver los problemas enfrentados por Austin y Hart. Shapiro denomina su teoría como la teoría del derecho como un plan.

En comparación con Austin y Hart, Shapiro está en una mejor posición para explicar el derecho como una práctica social. Para ello puede emplear algunos de los avances antes mencionados en el campo de la ontología social. De hecho, su teoría del derecho como un plan está influenciada por la teoría de las intenciones y, en particular, la teoría de las intenciones compartidas y las actividades compartidas, de Michael Bratman ${ }^{45}$.

La tesis principal de Shapiro es la tesis del planeamiento. De acuerdo con ella, "la actividad jurídica es una actividad de planeamiento social" 46 . Esto significa que

La actividad jurídica es más que una simple actividad de formulación, adopción, repudio, afectación y aplicación de normas por parte de los miembros de una comunidad. Es una actividad de planeamiento ${ }^{47}$.

En aras de defender esta tesis, Shapiro desarrolla dos teorías diferentes: la teoría de los planes y la teoría de la práctica jurídica como

${ }^{45}$ Michael Bratman desarrolla esta teoría del comportamiento intencional colectivo en una serie de artículos, sobre la base de su conocida teoría de las intenciones como planes. Sobre esta teoría, ver: Bratman, M., "Planning and the Stability of Intention", Minds and Machines, 2, 1992a. Los principales puntos de vista de Bratman se encuentran en cuatro trabajos: Bratman, M., "Shared Cooperative Activity", op. cit.; Bratman, M., "Shared Intention", Ethics, 104, 1, 1993; Bratman, M., "Shared Intention and Mutual Obligation", en Bratman, M., Faces of Intention, op. cit., págs. 130-141; y Bratman M., "I intend That We J", en Bratman, M., Faces of Intention, op. cit., págs. 142-161. 
Austin, Hart y Shapiro.Tres variaciones alrededor del derecho ...

una actividad de planeamiento social. Siguiendo la tradición del positivismo jurídico, Shapiro aduce que las reglas son planes, y que los planes están basados solo en hechos sociales. Su existencia depende de la adopción y la aceptación. Los planes se crean por medio de la adopción y se mantienen por medio de la aceptación. La existencia de un plan no depende de los méritos del contenido del plan, sino solo del hecho de que haya sido adoptado y aceptado ${ }^{48}$.

\section{IV.1. La teoría de los planes de Shapiro}

Primero es preciso examinar la teoría de los planes de Shapiro. De acuerdo con esta teoría, los planes son normas. Son "entidades proposicionales abstractas que exigen, permiten o autorizan a los individuos a actuar o no actuar, de ciertas y maneras bajo ciertas condiciones" 49 . En este sentido, ellos asumen el mismo rol que las reglas hartianas: funcionan como "guía[s] de conducta y como estándare[s] de evaluación" 50 .

Según Shapiro los planes tienen 11 características:

1. Los planes son parciales y, de esta manera, tienen una estructura compleja que evoluciona con el tiempo: "Ellos comienzan como conchas vacías y, se vuelven más comprensibles y útiles en la medida en que a ellos se añaden más detalles" 51 .

2. Los planes son compuestos: "tienen partes que son planes en sí mismas" 52 .

3. Los planes ayudan a racionalizar el comportamiento futuro de quien los crea, así como de otras personas ${ }^{53}$.

${ }^{48}$ Shapiro, S., Legality, op. cit., pág. 195. Un problema que no abordaré aquí es que un plan no puede adoptarse sin antes existir. En este caso, por tanto, la adopción de un plan no puede explicar su existencia.

${ }^{49}$ Shapiro, S., Legality, op. cit., pág. 127.

${ }^{50}$ Shapiro, S., Legality, op. cit., pág. 127.

${ }^{51}$ Shapiro, S., Legality, op. cit., pág. 121.

${ }^{52}$ Shapiro, S., Legality, op. cit., pág. 130.

${ }^{53}$ Shapiro, S., Legality, op. cit., pág. 122. 
4. Los planes pueden diseñarse para otras personas. Es posible que quien crea un plan, no sea quien lo siga, es decir, quien finalmente lo aplique ${ }^{54}$.

5. Los planes reducen los costos deliberativos. Una vez establecido un plan, ya no necesito emprender una deliberación acerca del futuro curso de mis acciones. Los planes reemplazan la deliberación acerca de lo que debe hacerse. Tal como expone Shapiro: "el valor que tiene un plan es que piensa por nosotros" 55 .

6. Los planes generan normatividad en razón de ciertos principios de la racionalidad instrumental: si yo establezco un plan con el propósito de reemplazar la deliberación futura, es racional que yo me sujete a lo dispuesto por el plan, es decir, que lleve a cabo la acción requerida por él. De forma correlativa, es irracional que yo abandone al plan, a menos que una razón muy fuerte entre en juego y me lleve a ello.

7. Los planes son entidades positivas: "son creados por adopción y mantenidos mediante la aceptación" 56 .

8. Los planes son la estrategia más efectiva para coordinar el comportamiento relativo a actividades complejas, contenciosas y arbitrarias, es decir, actividades que exigen conocimientos y aptitudes especializadas, que pueden dar lugar a disputas, y pueden dar lugar a comportamientos impredecibles ${ }^{57}$.

9. Los planes pueden compartirse en el sentido de las actividades compartidas de Bratman ${ }^{58}$. Un plan es algo que varias personas pueden compartir.

${ }^{54}$ Shapiro, S., Legality, op. cit., pág. 126.

55 Shapiro, S., Legality, op. cit., pág. 127.

56 Shapiro, S., Legality, op. cit., pág. 128.

57 Shapiro, S., Legality, op. cit., págs. 133-134.

${ }^{58}$ Shapiro, S., Legality, op. cit., pág. 135. De acuerdo con Bratman, para que una actividad sea una actividad cooperativa compartida, esta tiene que cumplir tres exigencias: (1) que exista entre todos los agentes implicados mutua receptividad en cuanto a la persecución del fin común, es decir, mutua receptividad frente a las intenciones y acciones de los otros agentes; (2) que exista en todos los agentes implicados un compromiso de formar parte de la actividad cooperativa. Bratman sostiene que es necesario que los sub-planes de los agentes 
Austin, Hart y Shapiro.Tres variaciones alrededor del derecho ...

10. Los planes pueden ser jerárquicos. Permiten las divisiones verticales del trabajo ${ }^{59}$.

11. Los planes pueden regular actividades masivas. Ellos compensan la desconfianza que pueda surgir entre los miembros del grupo en la realización de actividades masivas ${ }^{60}$.

\section{IV.2. La actividad jurídica como una forma de planeamiento social}

La segunda teoría de Shapiro es una teoría del derecho que se basa en su teoría de los planes. Shapiro desarrolla su teoría en dos pasos, mediante el empleo de una situación hipotética similar a la del bien

encajen de manera tal que los sub-planes de unos agentes no vulneren los sub-planes de otros agentes. También es necesario que las intenciones de todos los agentes sean interdependientes. Es preciso que cada agente procure que el grupo lleve a cabo la acción de acuerdo con el plan del grupo y con los subplanes de cada uno de los agentes participantes. Adicionalmente, se necesita que los agentes se comprometan a conectar o engranar sus propios planes con los planes de los demás. Sin embargo, esto no puede llevarse a cabo mediante coacción. Finalmente, en caso de que usted y yo seamos miembros del grupo que está llevando a cabo una acción intencional colectiva, para que nuestra acción común (J-ing) pueda ser una actividad cooperativa compartida, yo debo tener la intención de que nosotros hagamos $J$ en parte por sus intenciones de que nosotros hagamos J y sus subplanes. Bratman también sostiene que las actividades cooperativas compartidas involucran una interlocución apropiada y un sistema reflexivo de intenciones mutuamente no coaccionadas en relación con la actividad mancomunada; por último, (3) los agentes deben comprometerse a apoyarse mutuamente, es decir, deben adquirir el compromiso a respaldar el esfuerzo de otros agentes que participan en la actividad y que desempeñan sus propios papeles. Si una acción llevada a cabo por varios agentes no cumple con estos requisitos, entonces la acción no es una actividad cooperativa compartida, sino solo una acción intencional conjunta. Al compartir las actividades cooperativas, las intenciones de los agentes tienen que ser cooperativas y mínimamente estables. Una intención es cooperativa y mínimamente estable si existen circunstancias cooperativamente relevantes en las que el agente pueda retener esa intención. Ver Bratman, M., "Shared Cooperative Activity", op. cit., p. 327.

${ }^{59}$ Shapiro, S., Legality, op. cit., pág. 141.

${ }^{60}$ Shapiro, S., Legality, op. cit., pág. 143 y ss. 
conocido estado de naturaleza. En primer lugar, Shapiro da una explicación de cómo puede crearse un sistema jurídico mediante la adopción y la aceptación de planes. En el segundo paso, usando una metodología de análisis conceptual, Shapiro aclara cuáles son las propiedades esenciales de una actividad jurídica como una forma de actividad social.

IV.2.1. El derecho en la isla de los cocineros

Shapiro explica el propósito de la situación hipotética del estado de naturaleza, que en su libro se concreta en una sociedad imaginaria de cocineros que crean una sociedad en una isla del pacífico sur: la isla de los cocineros. El ejemplo se usa para demostrar que lo único necesario para construir un sistema jurídico "es la intervención humana"61. Shapiro considera que si ello es así, entonces esto demuestra que la tesis del positivismo jurídico es correcta, por la siguiente razón:

... para construir u operar un sistema jurídico no se necesita tener legitimidad moral para imponer obligaciones jurídicas y conferir derechos: solo se necesita la capacidad de crear planes $^{62}$.

La narración de la situación hipotética de la isla de los cocineros comienza con dos personas que cocinan juntas y que deciden crear una empresa de comida. La compañía se vuelve muy exitosa y termina contratando una gran cantidad de empleados y produciendo grandes dividendos. Sin embargo, los dueños y los empleados deciden vender la compañía y trasladarse a la isla del pacífico sur. En aquella isla, dadas las complejidades y la ausencia de coordinación, la vida sin reglas demuestra ser altamente inconveniente. Por esta razón, comienzan a crear planes. No obstante, esto genera un alto costo de deliberación y negociación. Para paliar este costo, ellos crean un plan maestro, es decir, un plan de planes. Adicionalmente, crean jerarquías 
Austin, Hart y Shapiro.Tres variaciones alrededor del derecho ...

mediante la atribución de poderes a algunas personas para planear a nombre del grupo. Pero, dado que incluso esta atribución de poderes es defectuosa, dado que las autoridades pueden morir, retirarse o quedar física o mentalmente discapacitadas, ellos deciden crear instituciones, es decir, "estructuras abstractas de control", diseñadas para cumplir ciertas funciones. Shapiro denomina coloquialmente a estas instituciones: "la oficina"63. Dado que "la oficina" prueba ser una invención exitosa, se crean diferentes oficinas; mientras que la función de algunas de ellas es la adopción de planes, otras los implementan y los aplican. Quienes adoptan los planes crean directrices para la regulación del comportamiento y políticas para atribuir competencias a las personas para que ellas puedan planear por sí mismas.

IV.2.2. Características esenciales del derecho

\section{a. La coerción no es una característica esencial del derecho}

Cuando se crean las instituciones, sostiene Shapiro, se da lugar al mismo tiempo a un sistema jurídico. Su explicación es la siguiente:

En este punto, parece seguro afirmar que la Isla de los cocineros ha desarrollado un sistema jurídico. Quienes hacen los planes son las autoridades oficiales; quienes adoptan los planes son los legisladores; y quienes aplican los planes son los jueces. El plan maestro es la constitución que define sus competencias. Los planes creados y aplicados por estas autoridades oficiales, de conformidad con el plan común, constituyen las leyes del sistema: las directrices políticas son las reglas que imponen deberes y las políticas de autorización son las que confieren competencias. Finalmente, los isleños actúan todos de acuerdo con el plan. Son ciudadanos que respetan el derecho ${ }^{64}$.

De esta afirmación, Shapiro deriva la conclusión de que la coerción no es una característica necesaria del derecho. Su idea

${ }^{63}$ Shapiro, S., Legality, op. cit., pág. 166.

${ }^{64}$ Shapiro, S., Legality, op. cit., pág. 169. 
es que la historia de la isla de los cocineros prueba la posibilidad de la existencia de un sistema jurídico desprovisto de sanciones. Adicionalmente, Shapiro piensa que el uso de la coerción es la vía más costosa, ineficaz y peligrosa para combatir lo que él ha denominado el problema del mal carácter, es decir, de la trasgresión de las normas morales ${ }^{65}$. Naturalmente, este autor no descarta el uso de la coerción en el derecho. De hecho, sostiene que algunas veces el derecho usa la coerción y que, cuando lo hace, la usa de una manera organizada. Lo que Shapiro defiende es que puede haber derecho desprovisto del uso de la fuerza.

No obstante, entonces, surge una pregunta relevante: si la coerción no es una característica necesaria del derecho, y, dado que esta es una propiedad que ha sido tradicionalmente usada para distinguir los sistemas jurídicos de otros tipos de sistemas normativos como los sistemas morales o religiosos, o de etiqueta, entonces, ¿cuál es la característica específica del derecho, es decir, la propiedad que hace al derecho ser lo que es y no otra cosa? El todo que forman quienes hacen los planes, quienes los adoptan, quienes los aplican, un plan maestro, los planes, las directrices políticas, las políticas de autorización y los destinatarios de los planes se encuentran también en otras actividades de planeamiento, como los deportes, los juegos, las iglesias y los clubes sociales organizados. Entonces, ¿qué es lo que hace al derecho diferente de estas otras actividades de planeamiento?

\section{b. La tesis del propósito moral}

Shapiro sostiene que la característica específica del derecho que la distingue es su propósito ${ }^{66}$. Esto se denomina la tesis del propósito moral. De acuerdo con esta tesis:

${ }^{65}$ Shapiro, S., Legality, op. cit., pág. 174.

${ }^{66}$ Shapiro, S., Legality, op. cit., pág. 215: el propósito moral "es central para la identidad del derecho". En la misma página, Shapiro sostiene que "si queremos explicar qué hace al derecho ser derecho, debemos reconocer la necesidad de perseguir una finalidad moral"; "es parte de la identidad del derecho tener un misión moral". 
Austin, Hart y Shapiro.Tres variaciones alrededor del derecho ...

El propósito fundamental de la actividad jurídica es solucionar las deficiencias morales de las circunstancias de legalidad ${ }^{67}$.

Shapiro desarrolla esta idea de la siguiente manera:

... los sistemas jurídicos son instituciones de planeamiento social y su propósito fundamental es compensar las deficiencias de las formas alternativas de planeamiento en las circunstancias de legalidad ${ }^{68}$.

Al hacer una analogía con las bien conocidas "circunstancias de la justicia" de Rawls ${ }^{69}$, Shapiro sostiene:

Las circunstancias de legalidad se obtienen siempre que una comunidad tiene numerosos y serios problemas morales cuyas soluciones son complejas, contenciosas y arbitrarias ${ }^{70}$.

Shapiro considera que es posible afrontar la necesidad de regular el comportamiento, dentro del marco de la existencia de estos problemas, mediante varias estrategias: la improvisación, la organización espontánea, o incluso mediante otras formas de planeamiento no jurídicas, como, por ejemplo, los acuerdos privados, los consensos comunales o las jerarquías personalizadas. Sin embargo, desde el punto de vista de Shapiro, esto podría generar altos costos y grandes riesgos. El propósito del derecho es compensar las deficiencias de las formas de planeamiento no jurídicas. Y la forma mediante la cual es posible para el derecho llevar a cabo esta tarea es, en palabras de Shapiro, "planear de la manera 'correcta', a saber, por medio de la adopción y aplicación de planes moralmente sensibles en una forma moralmente legítima"71. El propósito del derecho es reducir los riesgos de que sean adoptados

${ }^{67}$ Shapiro, S., Legality, op. cit., págs. 213-214.

${ }^{68}$ Shapiro, S., Legality, op. cit., pág. 171.

${ }^{69}$ Rawls, J., A Theory of Justice, Cambridge, Mass., Cambridge UP, 1999, p. 109.

${ }^{70}$ Shapiro, S., Legality, op. cit., pág. 170.

${ }^{71}$ Shapiro, S., Legality, op. cit., pág. 171. 
malos planes, no en relación con un problema moral específico, sino con todos los posibles problemas morales.

\section{c. Las reglas fundamentales del sistema jurídico como planes compartidos}

Una segunda característica esencial del derecho, de acuerdo con Shapiro, es que las reglas de un sistema jurídico constituyen un plan compartido. Los miembros de un grupo diseñan este plan con el fin de incorporarse en una actividad conjunta con libre acceso al público y aceptada por la mayoría de los miembros del grupo. De acuerdo con Hart, los miembros del grupo son solo las autoridades oficiales y no todos los miembros de la sociedad. Por esta razón, sus intenciones y acciones compartidas constituyen las reglas fundamentales del sistema jurídico. En palabras de Shapiro:

Si queremos descubrir la existencia o el contenido de las reglas fundamentales de un sistema jurídico tenemos que mirar únicamente los [...] acontecimientos sociales y a lo que las autoridades oficiales piensan, proponen, sostienen y llevan a cabo en ese lugar ${ }^{72}$.

El contenido de estas reglas fundamentales no depende de ningún aspecto moral. El plan compartido puede ser incluso "moralmente reprochable". Esto es así, porque si fuese de otra forma, es decir, si un plan dependiera de aspectos morales, no podría resolver los desacuerdos ni reducir la arbitrariedad y la complejidad, dado que los miembros del grupo se verían involucrados en discusiones acerca de si tales aspectos morales son apropiados y si han sido de hecho aceptados.

Sin embargo, la afirmación anterior nos conduce a la pregunta de cómo podría ser esto compatible con la idea de que la propiedad específica del derecho es su propósito moral. ¿Cómo es posible que la práctica jurídica tenga un propósito moral, es decir, que persiga la adopción del plan correcto y, al mismo tiempo, permita los planes 
Austin, Hart y Shapiro.Tres variaciones alrededor del derecho ...

moralmente reprochables? La respuesta de Shapiro a estas preguntas es la siguiente: "Lo que hace que el derecho sea derecho es que tiene un propósito moral, no que este satisfaga ese propósito". ${ }^{73}$

\section{d. La posibilidad de la autoridad jurídica}

La tercera característica esencial del derecho es que "alguien tiene autoridad jurídica solo si está autorizado por el plan maestro de un sistema jurídico particular". Esta es una condición necesaria pero no es una condición suficiente. Para que alguien tenga autoridad jurídica, los miembros de la comunidad tienen también que estar dispuestos "a seguir las normas creadas [por la autoridad jurídica] para orientar su conducta"74. De esta manera, las autoridades jurídicas deben tener también la habilidad para motivar a los sujetos a obedecer el derecho ${ }^{75}$. La primera condición se obtiene cuando los miembros de una comunidad se comprometen a someterse a una persona o a un conjunto de personas establecidas como autoridad jurídica. La segunda se obtiene cuando existe racionalidad instrumental. Dado que los miembros de la comunidad han autorizado a las autoridades jurídicas a planear por ellos, la racionalidad instrumental les exige obedecer los planes por ellas establecidos.

\section{e. La normatividad del derecho}

Esto se relaciona con la cuarta característica esencial del derecho. En la teoría del derecho como un plan, la normatividad del derecho es solo un asunto de racionalidad instrumental. Shapiro sostiene que "la normatividad del plan maestro de un sistema jurídico es de una clase muy limitada"76. Shapiro está de acuerdo con Hart en que las reglas fundamentales de un sistema jurídico existen solo si las autoridades

73 Shapiro, S., Legality, op. cit., pág. 214.

${ }^{74}$ Shapiro, S., Legality, op. cit., págs. 179-180.

${ }^{75}$ A lo mejor es suficiente que los sujetos estén motivados a obedecer a las autoridades jurídicas y no que dichas autoridades sean, de hecho, razón para la motivación.

76 Shapiro, S., Legality, op. cit., pág. 182. 
oficiales adoptan una actitud de aceptación frente a ellas. No obstante, Shapiro impone una restricción adicional. Dado que las reglas fundamentales son elementos de un plan compartido, ellas necesitan que las autoridades oficiales tengan una actitud más compleja hacia ellas que la del punto de vista interno de Hart. En sus palabras:

... la aceptación de un plan implica más que un simple compromiso de cada quien de poner de su parte: cada individuo debe también comprometerse a permitir que otros hagan su parte. Además, aceptar la parte propia implica la adopción de un plan. En otras palabras, aceptar la parte que a un individuo le corresponde no es un simple compromiso personal de seguir el plan; ese individuo también se compromete a ejecutar el plan, a asegurarse de su compatibilidad con las convicciones propias, con los subplanes, y con otros planes, y a no reconsiderarlo en casos de ausencia de una razón que irresistiblemente lo obligue a hacerlo ${ }^{77}$.

Entonces, la actitud que las autoridades oficiales deben tener, de acuerdo con la teoría del derecho como un plan, es la de aceptación de las reglas fundamentales, y esto implica "la adopción de los planes". Y Shapiro sostiene que con esto entran en juego las normas de la racionalidad instrumental que conciernen a la actividad de planeamiento. A las autoridades oficiales se les exige sujetarse a lo dispuesto por los planes y a no provocar una nueva deliberación, a menos que haya una "razón que obligue a hacerlo"78. Shapiro denomina estas exigencias de racionalidad de los sistemas jurídicos la "racionalidad interna del derecho". Entonces, la normatividad del derecho consiste en la obligación de permanecer dentro de esta racionalidad interna. Ella no es necesariamente una normatividad moral por lo que "no hay razón para pensar que los planes maestros de todo sistema jurídico posible serán moralmente legítimos"79. Como consecuencia, las autoridades jurídicas no tienen el poder de crear e imponer obligaciones morales.

77 Shapiro, S., Legality, op. cit., pág. 183.

78 Shapiro, S., Legality, op. cit., pág. 183.

79 Shapiro, S., Legality, op. cit., pág. 184. 
Austin, Hart y Shapiro.Tres variaciones alrededor del derecho ...

Ellas solo tienen el poder de imponer obligaciones jurídicas desde un punto de vista jurídico. Dichas obligaciones solo son vinculantes (siempre que su naturaleza jurídica se mantenga) desde el punto de vista jurídico, pero no desde el punto de vista moral.

\section{f. Otras características específicas del derecho como planeamiento social}

Sobre la base de todas estas premisas, Shapiro también define la actividad jurídica como una actividad de planeamiento social con otras características específicas, esto es, con propiedades que nos permiten distinguirla de otras actividades de planeamiento. Estas características son las siguientes:

1. En cuanto planes, las normas jurídicas crean una organización ${ }^{80}$. Ellas son normas positivas que resuelven desacuerdos morales sobre lo que debe llevarse a cabo. A menos que existan razones que así lo impongan, a este nivel, la remisión que a ellas se haga previene la deliberación, la discusión o la negociación.

2. En cuanto planes, las normas jurídicas son dispositivas ${ }^{81}$. Ellas disponen a sus destinatarios para que las obedezcan. Esta propiedad encarna la condición de eficiencia mínima que todo derecho debe cumplir.

3. La actividad jurídica como actividad de planeamiento tiene un propósito concreto. Este propósito es crear normas ${ }^{82}$.

4. La actividad jurídica es una actividad de planeamiento social en tres sentidos diferentes: "crea y administra normas que representan estándares comunes de comportamiento"; "regula la mayoría de la actividad común por medio de políticas generales"; y "regula la mayoría de las actividades comunes por medio de la estándares públicos" 83 . 
5. La actividad jurídica es una actividad compartida. Shapiro explica esta afirmación en el siguiente sentido: "la actividad jurídica es una actividad compartida en la que varios actores jurídicos involucrados desempeñan ciertos roles en la propia actividad de planeamiento social: algunos participan mediante la creación y modificación de planes y otros participan mediante su aplicación" ${ }^{84}$.

No obstante, con esto Shapiro no quiere defender la tesis de que la actividad jurídica sea una actividad intencional compartida. Este autor sostiene que las autoridades oficiales no necesitan tener la intención de involucrarse en esta actividad para de hecho hacerlo. Ellos pueden involucrarse en la actividad jurídica estando completamente alienados en el proceso, es decir, solo mediante la ejecución de sus funciones. No es necesario que las autoridades acepten el plan maestro.

La tesis de la actividad compartida ayuda a entender que las autoridades oficiales son miembros de grupos y, como consecuencia, miembros de un sistemas jurídico específico (por ejemplo, son miembros del sistema jurídico de los Estados Unidos y no del sistema jurídico inglés o francés).

1. El diseño del plan maestro no necesita un acuerdo completo entre todas las autoridades oficiales. Solo necesita que, por lo menos, una parte de las autoridades oficiales diseñen al menos una parte del plan maestro ${ }^{85}$.

2. La unidad del sistema jurídico. Existe unidad en un sistema jurídico cuando este es compatible con todas las normas derivadas de la actuación colectiva de las autoridades oficiales. Como consecuencia, el derecho de un cierto sistema consiste en el plan maestro y unos planes creados de acuerdo con este ${ }^{86}$.

${ }^{84}$ Shapiro, S., Legality, op. cit., pág. 204.

85 Shapiro, S., Legality, op. cit., pág. 207.

${ }^{86}$ Shapiro, S., Legality, op. cit., pág. 208. 
Austin, Hart y Shapiro.Tres variaciones alrededor del derecho ...

3. La actividad jurídica es una actividad oficial. Los agentes del derecho ocupan oficinas ${ }^{87}$.

4. La normatividad del derecho es institucional. No depende de las intenciones de las autoridades oficiales, sino de las autorizaciones que ellas reciben para crear normas jurídicas y de los planes que explican cómo deben utilizarse tales autorizaciones. Las intenciones son remplazadas por los procedimientos ${ }^{88}$.

5. El resultado del ejercicio de la autoridad jurídica es obligatorio para los sujetos de un sistema jurídico. No es una condición necesaria el consentir con lo decidido por la autoridad jurídica para estar sujeto a los planes establecidos por ella. Estos planes son vinculantes desde el punto de vista jurídico ${ }^{89}$.

6. El derecho tiene un propósito moral independiente del propósito moral de los participantes jurídicos. Shapiro defiende que en el mismo sentido en que las afirmaciones se proponen proveer información veraz a pesar de que el emisor pueda estar mintiendo, es "una verdad esencial del derecho que su propósito es resolver problemas morales" ${ }^{90}$. Shapiro sostiene que esto es posible por la siguiente razón, que dada su gran importancia para el propósito de este artículo, a pesar de su longitud, se citará en su totalidad:

El propósito que el derecho tiene, lo tiene porque las autoridades oficiales de alto rango representan a la práctica como una práctica que tiene uno o varios propósitos morales. Sus afirmaciones no necesitan ser honestas sino ser proferidas. Estas representaciones pueden tomar muchas formas: discursos explícitos, estelas ceremoniales, preámbulos de constituciones, prólogos de códigos jurídicos, y sentencias judiciales, o formas implícitas: atmósferas de atuendos rituales y discursos, la construcción de edificios monumentales que alojan la actividad jurídica, y el uso de iconografía religiosa o moral en los sitios en los que se crea o se profiere el derecho. Quizás, y esto es lo más

Shapiro, S., Legality, op. cit., pág. 209.

Shapiro, S., Legality, op. cit., pág. 211.

Shapiro, S., Legality, op. cit., pág. 212.

Shapiro, S., Legality, op. cit., pág. 216. 
importante, los propósitos morales del derecho se representan por medio del discurso jurídico. Mediante la descripción de las demandas jurídicas como 'obligaciones' y no simplemente como 'deberes morales', y del poder como algo que se basa en el ejercicio de los 'derechos' y no simplemente como meras 'posibilidades', las élites presentan su práctica como algo más que una mera empresa criminal o como la búsqueda egoísta de placer, de lucro o de gloria ${ }^{91}$.

7. El derecho se auto-certifica en el sentido de que contiene una presunción general de validez.

\section{IV.3. El derecho como práctica social en la teoría del derecho como un plan}

La teoría del derecho como un plan es, sin lugar a dudas, la postura más desarrollada del derecho como práctica social. Shapiro logra explicar la práctica jurídica como una entidad socio-ontológica por medio del entendimiento de las actividades jurídicas como actividades de planeamiento. Desde el punto de vista de Shapiro, el planeamiento de actividades es una práctica social, es decir, un conjunto de acciones intencionales colectivas. El compartir un plan, en cada una de sus instancias posibles, a saber, diseñarlo, aplicarlo y hacerlo cumplir, implica llevar a cabo una acción intencional colectiva. Primero, el compartir un plan es algo que los miembros de un grupo solo pueden hacer juntos. De manera contraria a lo que el concepto de hábito general de obediencia de Austin y el concepto de aceptación de reglas de Hart implican, el concepto de Shapiro de compartir un plan no permite una lectura distributiva. Este concepto es colectivo, y ello no da lugar a ninguna ambigüedad. Mediante el diseño y desarrollo de un plan, todos los miembros de un grupo cumplen intencionalmente con su parte, y solo por esta razón es que el plan logra ser diseñado y desarrollado. Segundo, la existencia de un plan compartido es de conocimiento común. Es imposible compartir un plan sin conocer de 
Austin, Hart y Shapiro.Tres variaciones alrededor del derecho ...

su existencia. Finalmente, para compartir un plan los miembros del grupo deben contar con una actitud cooperativa: la actitud de aceptación del plan. Como lo explica Shapiro:

... un plan es compartido por un grupo solo si cada uno de los miembros del mismo, en algún sentido, 'acepta' el plan. Esto implica que cada uno de los miembros debe tener una actitud cooperativa en relación con que el plan de grupo se lleve a cabo mediante la acción individual de sus miembros ${ }^{92}$.

De acuerdo con Shapiro, la aceptación de un plan es una actitud cooperativa compleja de cada uno de los miembros del grupo que implica cuatro elementos: (1) un compromiso de llevar a cabo la parte propia; (2) un compromiso de permitir (e incluso ayudar) a otros miembros del grupo a hacer sus propias partes; (3) un compromiso de asegurar la consistencia entre el plan y otros cursos de acción posibles; y (4) un compromiso de seguir el plan y de no reconsiderarlo en ausencia de una razón suficiente para hacerlo.

Además, Shapiro hace un esfuerzo altamente original al adaptar la teoría de Bratman de las actividades cooperativas para explicar la práctica jurídica, que es una actividad masiva, que permanece en el tiempo, jerárquica, y en la cual la alienación y la deficiencia de acuerdo conceptual y teórico es ubicua. La teoría de Bratman, como la mayoría de las teorías de intencionalidad colectiva, persigue explicar acciones colectivas sencillas llevadas a cabo solo por dos o, como mucho, por un número reducido de agentes (como pintar una casa o caminar juntos), en la cual, ellos, en general, están de acuerdo en lo que hacen. En este respecto, la teoría del derecho como un plan es una contribución no solo a la teoría del derecho, sino también a la ontología social en general. Es un simple ejemplo de cómo algunos principios básicos de la ontología social pueden llegar a utilizarse como

${ }^{92}$ Shapiro, S., Legality, op. cit., pág. 135: "un grupo comparte un plan solo si el plan está diseñado, al menos en parte, por el grupo relevante, como una actividad conjunta se constituye mediante las acciones individuales de cada uno de sus miembros". 
explicaciones de actividades más complejas, tales como aquellas que están implícitas en la práctica jurídica.

En este sentido, Shapiro usa diversas estrategias apropiadas. Primero, no concibe la práctica jurídica como una actividad intencional colectiva única, sino como un conjunto de varias actividades intencionales colectivas llevadas a cabo por diferentes grupos: la creación de un plan maestro (por parte de los constituyentes), y su desarrollo mediante la creación de planes (por la vía del desarrollo legislativo), su ejecución (por parte del ejecutivo) y su aplicación (por vía judicial). Shapiro es capaz de ver que la práctica jurídica es una actividad altamente compleja que envuelve no solo una práctica genérica, como el hábito general de obediencia al soberano de Austin o la aceptación de la regla de reconocimiento hartiana por parte de las autoridades oficiales, sino también prácticas generales singulares y concretas llevadas a cabo por diferentes grupos.

El análisis de Shapiro también puede complementarse con la explicación de que las autoridades oficiales están organizadas en una multitud de grupos de diferentes niveles. Por ejemplo, los legisladores que crean los planes están organizados en grupos de representantes de primer orden que pertenecen a un partido, que a su vez están organizados en grupos de segundo orden: comisiones de representantes a la Cámara que a su vez pertenecen a un grupo de tercer orden: la Cámara de Representantes, que a su vez pertenece a un grupo de cuarto orden: el Congreso. Cada uno de estos grupos actúa mediante acciones intencionales colectivas llevadas a cabo por parte de los miembros del grupo. En los niveles de más alto orden, existen representantes que actúan en nombre de los miembros de los grupos de orden inferior.

Segundo, en la teoría del derecho como un plan, la estructura parcial, organizada y compuesta de los planes permite que exista una actividad colectiva intencional entre los miembros de un grupo entre quienes solo existe un débil acuerdo conceptual acerca de su actividad conjunta. Esto puede explicarse mediante un ejemplo. Para que usted y yo tengamos un plan de cocinar juntos esta noche, no es condición necesaria que estemos de acuerdo en cuanto a todos los detalles del plan (por ejemplo, en cocinar pescado, con especias hindúes, en mi 
Austin, Hart y Shapiro.Tres variaciones alrededor del derecho ...

casa, etc.). Esta característica es particularmente importante a la hora de explicar la naturaleza del derecho. Gracias a ella, la teoría del derecho como un plan no puede ser objeto de la objeción de Dworkin en contra del positivismo jurídico atinente a la existencia de desacuerdos teóricos ${ }^{93}$. La teoría del derecho como plan es capaz de explicar por qué pueden existir prácticas jurídicas a pesar de la existencia de desacuerdos entre los practicantes jurídicos acerca de las (tal como las denomina Dworkin) razones del derecho. Por el contrario, esta teoría es capaz de explicar el desacuerdo teórico como parte del proceso natural de deliberación y negociación entre los miembros de los grupos relevantes en la práctica jurídica con el propósito de llenar de contenido a los planes.

Tercero, la posibilidad de planear para otras personas, a saber, el hecho de que sea posible que un agente cree un plan para ser aplicado por otro agente distinto, permite a la teoría del derecho como un plan explicar tres intuiciones básicas acerca de la práctica jurídica, a saber, (1) que es una práctica masiva en la que no todos los miembros de la sociedad pueden participar en la creación de planes, y que, por consiguiente, la alienación de muchos ciudadanos al derecho no creado por ellos es un elemento inevitable de la práctica jurídica; (2) que esta es una práctica jerárquica en la que la existencia de las autoridades es posible y necesaria; y (3) que la práctica jurídica es, al menos en parte, heterónoma y normativa, en el sentido de que cada miembro de la sociedad tiene una obligación jurídica de seguir los planes creados para nosotros por parte de los legisladores.

No obstante, en este punto surgen dos preguntas relacionadas entre sí. Por una parte, de acuerdo con la teoría del derecho como un plan, ¿es necesario para la existencia de una práctica jurídica que cada una de las autoridades oficiales participe activamente mediante sus acciones individuales y sus intenciones cooperativas en las acciones de grupo relevantes para crear, ejecutar y aplicar los planes? Y por otra

${ }^{93}$ Dworkin, R., Justice in Robes, Cambridge, Mass., London, Belknap Press of Harvard University Press, 2006, págs. 151 y 156. Para una explicación de esta objeción, ver: Smith, D., "Theoretical Disagreement and the Semantic Sting”, Oxford Journal of Legal Studies, 30, 4, 2010. 
parte, ¿cuál es la fundamentación de la normatividad del derecho? Para que el derecho sea normativo, en el sentido de la normatividad racional instrumental de los planes, es necesario que todos los sujetos de derecho acepten todos los planes jurídicos o, por lo menos, el plan maestro. ¿Es esta una exigencia de la teoría del derecho como un plan?

En relación con la primera pregunta, Shapiro es consciente de que exigir dicha participación activa por parte de todas las autoridades jurídicas implicaría una asunción injustificada. Desde luego, existen ciertas acciones jurídicas en las que todos los miembros de un grupo satisfacen, de hecho, todas las exigencias de una acción intencional colectiva, incluso si se acepta el concepto de este tipo de acciones, defendida por la postura socio-ontológica más exigente. Por ejemplo, esto ocurre cuando la Corte Suprema profiere una sentencia en la que todos los jueces trabajan conjuntamente y de común acuerdo para juzgar un caso de acuerdo con el plan maestro (la Constitución). Sin embargo, no toda acción llevada a cabo por las autoridades oficiales exige este nivel de involucramiento por parte de los miembros de los grupos primarios, secundarios, terciarios, y otros. También sería inconveniente exigir este nivel de involucramiento porque eso podría restringir la posibilidad de que el derecho resuelva eficientemente situaciones complejas y contenciosas. Por esta razón, Shapiro sostiene plausiblemente que, con el tiempo, la práctica jurídica se convierte en institucional, y esto significa que en muchos casos las intenciones reales de las autoridades oficiales ya no son necesarias. Estas son remplazadas por los procedimientos ${ }^{94}$.

La segunda pregunta se relaciona con una objeción de Bruno Celano en contra de la teoría de Shapiro. En "¿Que pueden hacer los planes por la teoría jurídica?" 95 Bruno Celano sostiene que, desde el punto de vista de Bratman, los planes son producidos y aplicados por parte de los agentes para sus propias acciones y deliberaciones futuras. Son una herramienta de auto-administración. Por el contrario, la finalidad de la autoridad del derecho consiste, precisamente, en establecer 
Austin, Hart y Shapiro.Tres variaciones alrededor del derecho ...

y aplicar planes para otros. Por ello, la normatividad del derecho se aplica sobre todo hacia individuos distintos a aquellos que crearon las normas jurídicas. Consecuentemente, el concepto de plan de Bratman no puede usarse para analizar el derecho. No sería útil para el propósito de entender la naturaleza del derecho. En particular, Celano sostiene:

Shapiro ilegítimamente manipula la normatividad (bratmaniana) que un plan despliega para el agente, o agentes, que lo han adoptado para sí mismos, en aras de justificar que el derecho, también, es normativo ${ }^{96}$.

Si esto es cierto, entonces la teoría del derecho como un plan no puede explicar la normatividad del derecho en términos de normatividad instrumental emanada de los planes. Como explica Celano:

La racionalidad instrumental es una racionalidad relativa a la persecución de metas o fines. ¿Qué fines, qué metas? En el caso de los planes en primera persona, la respuesta es sin lugar a dudas: mis metas [...]. Pero, en el caso de los 'planes' adoptados para otros, aparece una alternativa: ¿estamos hablando de normas que son instrumentalmente racionales para quien planea, o para aquellos para quienes se adoptan los 'planes'? A menos que supongamos - y esta es una presunción injustificada - que estas dos cosas coinciden, debemos reconocer que lo que es instrumentalmente racional para quien adopta el plan para sí mismo puede no ser instrumentalmente racional para los otros, o viceversa ${ }^{97}$.

En una entrevista reciente para el Journal Legal Theory in China ${ }^{98}$, Shapiro replicó a Celano con el argumento de que ... tratar a los planes como algo interesante solo por el papel normativo singular que tienen para el actuar individual implica

${ }^{96}$ Celano, B., op. cit.

${ }^{97}$ Celano, B., op. cit.

${ }^{98}$ Disponible on line en: http://www.legal-theory.net/1327.html(05/25/2011). Agradezco a Scott Shapiro por permitirme acceder a este texto en inglés. 
adoptar una comprensión extremadamente reducida de los planes. Es ignorar su aspecto 'tecnológico'.

No es difícil reconocer una semejanza entre esta objeción en contra de la teoría del derecho como un plan y la objeción en contra de la idea del derecho de Hart como práctica social y no como práctica oficial. La objeción en contra de Hart es que la teoría no explica por qué las reglas sociales aceptadas por las autoridades oficiales no son vinculantes solo para ellas, sino también para los ciudadanos. La objeción de Celano parece ser incluso más severa. Desafía la posibilidad de que los planes sean colectivamente normativos o, en términos más sencillos, la posibilidad de planear para otros.

Legality contiene una respuesta plausible a la objeción de Celano. Es posible que alguien planee no solo para sí mismo sino también para otros miembros de su grupo si, como sostiene Shapiro, "en vez de formular y adoptar sus propios planes, los miembros del grupo aceptan un plan consistente en que ellos se sujetarán a lo que otro ha planeado" 99 . Esta es una posibilidad sensible que permitiría, al mismo tiempo, reconocer los aspectos tecnológicos de los planes, y el mantenimiento de su normatividad instrumental. Mi aceptación del plan según la cual me someteré a lo que otro planee para mí crea una obligación instrumental de sujeción a quien adopte el plan.

Sin embargo, la extrapolación de esta posibilidad de explicar la normatividad del derecho es un asunto más complejo, dado que la práctica jurídica es una actividad masiva, que se extiende en el tiempo. Una extrapolación estricta exigiría que todos los sujetos del derecho adopten el plan maestro que confiere a las autoridades oficiales el poder para crear, ejecutar y aplicar los planes jurídicos. Asumir que todos los sujetos del derecho despliegan una actividad intencional consistente en adoptar el plan maestro es inseguro. No existe un solo país en el que la redacción de una constitución sea el resultado de una acción intencional colectiva en la que todos los sujetos del derecho participen de hecho activamente con sus intenciones comunes y sus 
Austin, Hart y Shapiro.Tres variaciones alrededor del derecho ...

acciones, en forma de una acción grupal. Y Shapiro, de hecho, no asume esto. Sostiene en cambio que solo las autoridades oficiales son miembros del grupo que debe adoptar el plan maestro ${ }^{100}$.

Entonces, en estas condiciones, ¿cómo pueden las autoridades jurídicas existir y cómo puede el derecho ser normativo? ¿Por qué los planes jurídicos que se crean conforme al plan maestro que solo ha sido adoptado por las autoridades oficiales son también vinculantes para los miembros de toda la sociedad?

En Legality se encuentran dos intuiciones relevantes para responder esta pregunta. Primero, en la narrativa de la isla de los cocineros, Shapiro sostiene que

\begin{abstract}
... no es necesario que la comunidad acepte el plan compartido para que éste sea adoptado [...]. Dado que nosotros [los habitantes de la Isla de los cocineros] consideramos moralmente legítimos a quienes planean, planeamos para permitir que quienes adoptan y aplican los planes, los adopten y apliquen para nosotros. Por esta razón, consideramos que el plan compartido es el 'plan maestro' del grupo ${ }^{101}$.
\end{abstract}

Si generalizamos esto, entonces lo que fundamenta a la autoridad jurídica y la normatividad del derecho es el hecho de que los sujetos de derecho consideren "moralmente legítimo" que las autoridades oficiales creen el plan maestro y que ellos planeen permitir que estas autoridades jurídicas creen los planes que han de regir a toda la sociedad. Independientemente del problema de determinar el significado de "moralmente legítimo" dentro de este contexto, este requisito puede ser apropiado para una sociedad relativamente pequeña, pero parece demasiado estricto si lo aplicamos a cualquier sociedad moderna. Por esta razón, en su caracterización de las propiedades esenciales del derecho, Shapiro lo menciona solo como una posibilidad pero no como un requisito: los miembros de una comunidad

100 Shapiro, S., Legality, op. cit., pág. 119: "la existencia de la autoridad jurídica [...] depende de si las autoridades oficiales relevantes de ese sistema aceptan o no un plan que autorice y exija deferencia a tal organismo".

101 Shapiro, S., Legality, op. cit., pág. 165. 
"pueden todos aceptar una política general de obedecer el derecho o considerar aquellos en posición de autoridad como moralmente legítimos"102.

Por otra parte, Shapiro parece indicar que la normatividad del derecho dependerá de dos condiciones más débiles en relación con los sujetos del derecho: la disposición de los miembros de la comunidad para seguir los planes adoptados de acuerdo con el plan maestro ${ }^{103}$; y el hecho de que los miembros de la comunidad "reconozcan normalmente a aquellos que se encuentran en posición de autoridad"104. La combinación de las dos condiciones debe interpretarse como una aceptación tácita del plan maestro. Esta aceptación tácita debe fundarse en actividades intencionales colectivas y en actividades no intencionales de carácter colectivo. Muchos ciudadanos aceptan intencionalmente el plan maestro. Sin embargo, el plan maestro también puede aceptarse de forma no intencional. De la misma manera en que todos, sin intención, contaminamos el medioambiente cada vez que encendemos nuestro coche o utilizamos un spray, todos, como miembros de la comunidad, tácitamente y sin intención, creamos una actitud de aceptación del plan maestro de nuestro sistema jurídico, cada vez que aceptamos el derecho y el uso del mismo en nuestro razonamiento práctico. Si esto es cierto, entonces la práctica jurídica es algo que las autoridades oficiales hacen juntas intencionalmente, porque nosotros, miembros de la comunidad, algunos de manera intencional y algunos sin intención, pero todos juntos, les atribuimos poder para hacerlo.

\section{Agradecimiento}

Este trabajo forma parte de un proyecto mayor sobre ontología social y la naturaleza del derecho, financiado por un premio de investigación de la Universidad de Macquarie en Sídney, Australia. Escribí algunas

102 Shapiro, S., Legality, op. cit., pág. 181.

103 Shapiro, S., Legality, op. cit., pág. 179: "a menos que los miembros de una comunidad estén dispuestos a seguir las normas creadas para orientar su conducta, tales normas no podrán ser planes". 
Austin, Hart y Shapiro.Tres variaciones alrededor del derecho ...

de las secciones de este trabajo durante una estancia de investigación en la Facultad de Derecho de la Universidad de Yale. Agradezco a mi anfitrión en Yale, Scott Shapiro, por sus valiosos comentarios y sugerencias. Asimismo, debo agradecer a otras personas por sus críticas y aportes a los borradores de este trabajo. Ellas son: Kirk Ludwig, Brian Bix, Stanley Paulson, David Copp, Marina Oshana, Denise Meyerson, Larry Solum, Kevin Walton, Euan MacDonald, Robert D'Amico, Ryan Zarhai, y los estudiantes y colegas que participaron en mis conferencias sobre este tema en el Congreso de la Sociedad Australiana de Filosofía del Derecho, celebrado en la Facultad de Derecho de la Universidad de Melbourne (en junio de 2010), en el Instituto Julius Stone de Teoría del Derecho de la Facultad de Derecho de la Universidad de Sídney (en abril de 2011), en el Centro de Estudios en Gobernanza por medio del Derecho de la Facultad de Derecho de la Universidad de Macquarie (en mayo de 2011), en el Departamento de Filosofía de la Universidad de la Florida (en junio de 2011), y el Congreso de la Sociedad Australiana de Filosofía del Derecho, celebrado en la Facultad de Derecho de la Universidad de Brisbane (en julio de 2011). Este trabajo ha sido publicado originalmente en inglés en la revista Rechtstheorie, n. ${ }^{\circ} 44$ (2013). Agradezco a esta revista el permiso para publicar esta traducción al castellano. También agradezco a María José Viana por su magnífica traducción de este texto.

\section{Bibliografía}

Austin, J., The Province of Jurisprudence Determined, Cambridge, Cambridge UP, 1995.

Bratman, M., "Planning and the Stability of Intention", Minds and Machines, 2, 1992a, págs. 1-16.

Bratman, M., "Shared Cooperative Activity". The Philosophical Review, 101, 2, 1992b, págs. 327-341.

Bratman, M., "Shared Intention", Ethics, 104, 1, 1993, págs. 97-113.

Bratman, M., Faces of Intention, Cambridge, Cambridge UP, 1999. 
Celano, B., "What can Plans do for Legal Theory?", en Canale, D. y Tuzet, G. (eds.), The Planning Theory of Law, London Springer, 2013.

Davidson, D., Essays on Actions and Events, Oxford, Oxford UP, 2001.

Dworkin, R., Justice in Robes, Cambridge, Mass., London, Belknap Press of Harvard University Press, 2006.

Edmundson, W. A., "Shmegality: A Review of Scott J Shapiro, Legality", Jurisprudence, 2, 1, 2011, págs. 273-291.

Fara, M., "Dispositions", Stanford Encyclopedia of Philosophy, 2006, http://plato.stanford.edu/entries/dispositions/, 08/08/2011.

Gilbert, M., On Social Facts, Princeton, Princeton University Press, 1989.

Gilbert, M., "Walking Together: A Paradigmatic Social Phenomenon", Midwest Studies in Philosophy, 15, 1, 1990, págs. 1-14.

Gilbert, M., Living Together. Rationality, Sociality, and Obligation, Lanham, Rowman and Littlefield, 1996.

Gilbert, M., "Social Rules: Some Problem's for Hart's Account and a New Appraisal", Law and Philosophy, 18, 1999, págs. 141-171.

Gilbert, M., Sociality and Responsibility: New Essays in Plural Subject Theory. Lanham, Md, Rowman \& Littlefield Publishers, 2000.

Gilbert, M., "Acting Together", en Meggle, G. (ed.), Social Facts and Collective Intentionality. Frankfurt a. M., Hänsel-Hohenhausen, 2002, págs. 53-72.

Hart, H. L. A., The Concept of Law, Oxford, Clarendon Press, 1994 [1961].

Kim, J., Supervenience and Mind. Selected Philosophical Essays, Cambridge, Cambridge UP, 1993.

Kutz, C., Complicity: Ethics and Law for a Collective Age, Cambridge, Cambridge UP, 2000.

Ludwig, K., "Foundations of Social Reality in Collective Intentional Behavior", en Tsohatzidis, S. (ed.), Intentional Acts and Institutional Facts. Essays on John Searle's Social Ontology, Dordrecht Springer, 2007, págs. 49-71.

Ludwig, K., Understanding Collective Action. From Individual to Institutional Agency, manuscrito sin publicar, 2011. 
Austin, Hart y Shapiro.Tres variaciones alrededor del derecho ...

Miller, S., "Joint Action", Philosophical Papers, 21, 3, 1992, págs. 275-279.

Miller, S., "Intentions, Ends and Joint Action", Philosophical Papers, 24, 1, 1995, págs. 51-67.

Miller, S., Social Action: A Teleological Account, Cambridge, Cambridge UP, 2001.

Murphy, M., "Book Review: Legality", Law and Philosophy, 30, 3, 2011, págs. 369-375.

Rawls, J., A Theory of Justice, Cambridge Mass, Cambridge UP, 1999.

Sanchez Brigido, R., "Collective Intentional Activities and the Law", Oxford Journal of Legal Studies, 29, 2, 2009, págs. 305-324.

Sánchez Brigido, R. E., Groups, Rules and Legal Practice, Dordrecht, London, Springer, 2010.

Schauer, F., "The Best Laid Plans", The Yale Law Journal, 120, 2010, págs. 586-621.

Searle, J. R., Intentionality. An essay in the philosophy of mind, Cambridge, Cambridge University Press, 1983.

Searle, J. R., "Collective Intentions and Actions", en Cohen, P., Morgan, J. y Pollack, M. (ed.), Intentions in Communication, Cambridge MIT Press, 1990, págs. 401-415.

Searle, J. R., The Construction of Social Reality, New York, Free Press, 1995.

Searle, J. R., "Social Ontology. Some Basic Principles", Anthropological Theory, 6, 1, 2006, págs. 12-29.

Searle, J. R., Making the Social World. The Structure of Human Civilization, Oxford-New York, Oxford University Press, 2010.

Shapiro, S., "What is the Internal Point of View?", Fordham Law Review, 75, 2006, págs. 1157-1170.

Shapiro, S., Legality, Cambridge, Harvard University Press, 2011.

Shapiro, S., "Interview for the Journal Legal Theory in China", 2011, http://www.legal-theory.net/1327.html, 05/25/2011.

Smith, D., "Theoretical Disagreement and the Semantic Sting", Oxford Journal of Legal Studies, 30, 4, 2010, págs. 635-661. 
Tamanaha, B. Z., What is "General" Jurisprudence? A Critique of Universalistic Claims by Philosophical Concepts of Law, manuscrito sin publicar, 2011.

Toh, K., "Hart's Expressivism and His Benthamite Project", Legal Theory, 11, 2005, págs. 75-123.

Toumela, R., "Actions by Collectives", Philosophical Perspectives, 3, 1989, págs. 471-496.

Toumela, R., The Philosophy of Social Practices: A Collective Acceptance View, Cambridge, Cambridge UP, 2002.

Toumela, R., "We-Intentions Revisited", Philosophical Studies, 125, 2005, págs. 327-369.

Toumela, R., The Philosophy of Sociality. The Shared Point of View, Oxford, Oxford UP, 2007.

Toumela, R. y Miller, K., "We-Intentions", Philosophical Studies, 53, 1988, págs. 367-389.

Tsohatzidis, S. L., "Introduction", en Tsohatzidis, S. L. (ed.), Intentional Acts and Institutional Facts. Essays on John Searle's Social Ontology, Dordrecht Springer, 2007, págs. 1-10.

Waldron, J., "Planning for Legality", Michigan Law Review, 109, 2011, págs. 883-902.

Wilkinson, M. A., "Is Law Morally Risky? Alienation, Acceptance and Hart's Concept of Law", Oxford Journal of Legal Studies, 30, 3, 2010, págs. 441-466. 